\title{
Review \\ Gamification in IT Service Management: A Systematic Mapping Study
}

\author{
Manuel Trinidad (D), Elena Orta *(D) and Mercedes Ruiz \\ Department of Computer Science and Engineering, University of Cadiz, Avenida de la Universidad de Cádiz 10, \\ 11519 Puerto Real, Spain; manuel.trinidad@uca.es (M.T.); mercedes.ruiz@uca.es (M.R.) \\ * Correspondence: elena.orta@uca.es
}

check for

updates

Citation: Trinidad, M.; Orta, E.; Ruiz M. Gamification in IT Service Management: A Systematic Mapping Study. Appl. Sci. 2021, 11, 3384. https://doi.org/10.3390/app11083384

Academic Editor: Federico Divina

Received: 24 February 2021

Accepted: 2 April 2021

Published: 9 April 202

Publisher's Note: MDPI stays neutral with regard to jurisdictional claims in published maps and institutional affiliations.

Copyright: (c) 2021 by the authors. Licensee MDPI, Basel, Switzerland. This article is an open access article distributed under the terms and conditions of the Creative Commons Attribution (CC BY) license (https:/ / creativecommons.org/licenses/by/ $4.0 /)$.

\begin{abstract}
Despite the benefits of adopting IT Service Management (ITSM) reference models, such initiatives do not always produce the expected results. The research literature in this area concludes that motivation, engagement, skills, experience, performance and willingness to change of the personnel involved are among the critical factors for an effective ITSM implementation. Gamification has the capability to improve people's motivation and engagement and to drive people's behavior to meet the objectives set. Besides, gamification is widely used in learning systems for increasing students' skills and competences. In the last years, many researchers have added gamification to their process improvement initiatives to increase the motivation and engagement of process participants and to address their behavior throughout the process. Thus, we consider that adopting gamification in ITSM processes can be an interesting area of study. In this paper, we conducted a systematic mapping study to analyze the actual state of research in the field of ITSM gamification and identify the key challenges that justify future research. The results of our study highlight the positive impact of adopting gamification in ITSM processes and that ITSM gamification is a novel an attractive research area with many action possibilities.
\end{abstract}

Keywords: IT Service Management; ITSM process implementation; gamification; systematic mapping

\section{Introduction}

Given that the use of Information Technology (IT) has been significantly enhanced over the last years, currently, the IT service providers industry is one of the most important industries. Increasingly more, organizations request more efficient technological services, and IT service providers need to focus on improving the quality of the services they provide and the relations with their customers [1,2]. IT Service Management (ITSM) is a process-oriented approach aimed to define, manage and deliver properly IT services to achieve business objectives [3] and ensure IT service quality to satisfy the service levels agreed with the customers [4,5]. With the purpose to offer a road map for adequately managing IT services, several ITSM-related theoretical process reference models have been developed [6,7], such as ISO/IEC 20000 [8,9], Capability Maturity Model for Services (CMMI-SVC) [10] and Information Technology Infrastructure (ITIL) [11]. The adoption of ITSM reference models enables IT service providers to enhance IT service quality and customer satisfaction, to decrease the service provision charges and to increase returns of investments [12,13]. Therefore, implementing an ITSM framework is crucial for IT organizations to maximize business opportunities and improve their competitive market position [14]. Given the popularity of ITSM frameworks, a growing number of companies are implementing ITSM reference models with the purpose of improving their ITSM processes [15-17]. Besides, to help IT companies evaluate and improve their processes, various models have been developed [18], such as CMMI-SVC [10], ISO/IEC 15504-8 [19] and TIPA for ITIL [20], among others.

The idea that the ITSM process improvement has a positive impact on the service quality has promoted important practice and research in this area [21-23]. There are many 
research papers in the field of ITSM model implementation. Most of them focus mainly on examining both the benefits of adopting these frameworks in real-world companies [16] and the critical success factors (CSF) for an adequate implementation [16,24]. IT companies can develop, maintain and deliver greater quality services, enhancing the efficiency of their processes and the productivity of their employees [25]. Thus, one of the factors that most influence the success of ITSM process implementation is the incorporation of adequate process management practices $[24,26]$. Iden and Eikebrok $[25,27]$ empirically demonstrated the strong positive effects that the use of process management practices, such as to establish process performance objectives and to systematically monitor the process performance metrics, have on the processes improvement.

On the other hand, improving certain human aspects are also very important for a successfully ITSM process adoption. For instance, it is necessary that IT managers and employees change their attitudes and acquire new behaviors aimed to increase their performances and meet the process objectives [28]. Likewise, other aspects that greatly influence ITSM adoption are the level of expertise, motivation and commitment of process participants and the communication and collaboration between them [27]. A Gartner study [29] also noticed that one of the factors that most affect IT service malfunctions is the lack of employee skills and competence. Thus, in ITSM adoption initiatives performing a suitable training of process stakeholders is also fundamental for filling these lacks [30,31].

Given that ITSM is a process-oriented approach and the human nature of many ITSM processes, gamification turns into a promising trend that can influence positively the success of ITSM process adoption. Since the second half of 2010, gamification has grown as a relevant approach that can be applied to modify and influence people's behaviors [32] and for enhancing people's motivations and engagement when performing activities [33,34]. Besides, gamification is considered one of the emergent teaching technologies in education and training [35]. In the specific context of process improvement, gamification means to include game elements in processes to motivate and engage process participants, and to promote in them the desired behavior for improving their performance [36]. Gamification has experienced an important evolution in the last years [32,34], and the relevance of gamification has also been noticed in the academic context. In fact, currently, gamification is a wide research area with numerous published papers in various application domains, such as marketing [37], e-banking [38], healthy lifestyles [39] and education/learning [40], among many others. Moreover, gamification applies to process improvements in different contexts, such as software engineering [41] and information systems [42].

Given the positive effects that gamification can have on process improvement initiatives and its capacity for enhancing the motivation and engagement of people, we consider that adopting gamification in ITSM processes is a research opportunity [43,44]. Since a review of the previous and relevant literature is fundamental and forms a strong base for increasing knowledge in an area [45], in this paper, we conducted a systematic mapping study to examine the current state of research regarding gamification in the field of ITSM and to locate breaches that justify further research. Although the results of this study show the positive impact of gamifying ITSM processes, the small number of research papers found and the limitations that most of them presented indicate that ITSM gamification is still a novel research field. This, along with the challenges identified, reflect the fact that researchers have, in ITSM gamification, a broad field to investigate.

The rest of this paper is structured as follows. Section 2 reviews the works related with ITSM processes gamification. Section 3 explains the research methodology used for performing the systematic mapping study and includes our research questions, the search and selection of primary studies and the data analysis. Section 4 reports the results of our review. Section 5 outlines the threats to validity. Lastly, Section 6 recaps the main outcomes and the challenges and opportunities identified in this research area. 


\section{Related Work}

Many research papers have examined the most influential factors on the success of ITSM processes implementation. For instance, the literature review presented in [30] noted that process evaluation, change management, training and skills of participants, communication and collaboration and information technology applications are critical success factors for an effective ITSM process implementation. In [27], their authors also highlighted that the expertise, engagement and willingness to change of IT personnel are also crucial aspects for the results of such a process implementation. These same authors demonstrated in [25] that a raised IT staff expertise and using quality software have positive effects on the advancement of ITSM. Ref. [46] also noticed that the social elements of the company, including people, skills and rewards, are as important as technology and processes to the success. Ref. [31] pointed to training IT employees for enhancing their competence and choosing the appropriate support tools as other influential factors. Other works, such as [47-50], focused on the importance of IT personnel motivation and commitment and explored the factors that most affected those aspects. Thus, the works above-mentioned noticed that between the factors most influencing the ITSM success are the personnel human factors, such as motivation, engagement, skills, experience, performance and willingness to change. To improve these human factors, it is necessary that IT employees are motivated, modify their attitude towards change and develop new skills and competences focused on gaining effectiveness and higher performance [28]. Besides, it is also paramount to enhance the corporate learning processes to increase IT employees' skills and competences.

In the last years, the incorporation of game elements in non-game contexts or gamification has gained considerable attention [34,51], and analysts forecast a future constant expansion of gamification [52]. Game design is increasingly being used to improve people's motivation and engagement and to address their behavior towards performance improvement $[51,53,54]$. Initially, gamification was mostly used in the marketing domain $[37,55,56]$, but currently, a significant amount of empirical studies indicate that gamification is widely adopted in other areas, such as education and training [33,57]. Besides, gamification is used for improving processes that have similar characteristics to ITSM processes, like software engineering processes $[36,58]$.

\subsection{Gamification in Software Engineering Processes}

The results of the literature review introduced in [59] revealed that the proposals of gamification for the improvement of software engineering processes presented an upwards trend. In this context, gamification can be considered a good strategy for improving the interest and motivation of developers in the realization of repetitive and nonattractive tasks [60]. Several papers presented literature reviews conducted in this context. For instance, the systematic mapping carried out by Pedreira et al. [61] concluded that most of the studies focused on gamifying the software development process and particular activities of the software requirement engineering ones. The results of this study showed that other process areas, such as project management, software testing and configuration management, captured less attention among researchers. Recently, Refs. [41,62] also published the results of literature reviews. On the one hand, Ref. [62] introduced a systematic mapping to explore the actual initiatives and challenges of using gamification in software engineering. The study outcomes indicated that gamification afforded benefits in processes such as requirement specification, development, testing, project management and support processes. Besides, this study presented evidence of gamification applications for improving several CMMI 2.0 Practices Areas. The authors concluded that the key benefit of using gamification in software engineering processes is the improvement of the software personnel's engagement and motivation to conduct tasks. On the other hand, the systematic mapping conducted in [41] aimed to research and report the state of the gamification use for enhancing software processes and to identify the main challenges to include gamification into the initiatives of software process improvement. The resulting 
challenges mainly focused on the complexity of gamifying software processes and the need for more empirical research.

Another group of studies presented gamification-based conceptual frameworks or models for the improvement of the software engineering processes. For example, Ref. [63] introduced a case study in which a company used a framework proposed by the authors to gamify the project management, requirement management and testing processes. The obtained results showed that the framework helped the company to integrate gamification in its work environment and, as consequence, to improve the engagement, motivation and performance of the professionals involved in the processes. Moreover, Ref. [64] proposed a model for enhancing the knowledge management process in software companies, and Ref. [65] introduced a gamified proposal for a software risk analysis in agile methodologies. The results obtained noticed the positive impact that gamification has on knowledge management and risk management processes. The proposal of Pedreira et al. [66] was very complete, since they designed an architecture for software engineering gamification and developed a gamification engine based on their proposal. The case study conducted in a real software development company showed that the gamification engine allowed the company to create a gamified workplace.

The following papers aimed to study how the motivation and engagement of software practitioners influence software process improvements. The works conducted by Herranz et al. in references $[36,58,67,68]$ noted that one of the main reasons for failure in software process improvement initiatives is the lack of motivation of the practitioners involved. In $[67,68]$, the authors presented a gamification framework that incorporates gamification in change management initiatives to increase the motivation and commitment of the software professionals. The framework was validated by quantitative methods, and the results indicated the positive effects of gamification on the change management process. In [36], the authors offered a more comprehensive version of the gamification framework introduced in their previous works $[67,68]$. They validated the approach through interviews with experts in gamification and software process improvement. The interviews outcomes verified the framework validity, as well as its utility for software process improvement and its alignment with standardized gamification methods. The results of the framework's implementation that Herranz et al. introduced in [58] highlighted that the model contributed to improve the performance of the software processes studied. In [69], the authors introduced a gamification and functional prototyping approach to support the motivation towards software process improvement and collected the most important outcomes of a pilot study performed for evaluating the proposal. In reference [63], García et al. presented a gamification strategy to increase the involvement and motivation of the staffs in small-sized software enterprises in process improvement initiatives. The gamification strategy was evaluated using quantitative and qualitative methods, and the results show the positive strategy impact on the involvement and motivation of the staffs. Finally, in [70], a gamification proposal for enhancing Scrum adoption was introduced. The results suggested that gamification can impact positively on practitioners' motivations by changing the atmosphere within the team.

\subsection{Gamification in Education and Learning}

Improving learning processes to increase IT employees' skills and performance is a relevant factor for an adequate ITSM processes implementation $[25,30]$. The vast amount of research works conducted on adding game elements in education and learning systems prove the usefulness of gamification in that field.

The systematic mapping conducted in [59] classified gamification publications in six main categories, education as the area where the most papers were found. This work concluded that gamification was one of the rising trends in education and that the large number of literature reviews published on the gamification of learning revealed the high interest of the academic community in that field. For instance, the literature review presented in [71] showed that gamification has been widely used all the educational levels, 
from primary school to higher education. Likewise, the findings of the systematic mapping introduced in $[72,73]$ suggested that most primary studies used gamification to increase the engagement of higher education students. The major educational domains of gamification identified by Dicheva et al. [73] were computer science, information technology, mathematics, science and engineering. Besides, the review findings showed that gamification has positive effects on students' engagement, attendance and participation. In [74], the authors conducted a systematic literature review of game-based learning systems, frameworks that integrate game design elements and the implementation of gamification in higher education. The objective was to identify how gamified learning systems can be used and categorize their usefulness in higher education.

Some researchers have published empirical studies that prove the benefits of using gamification in an educational and learning context. For instance, the study conducted in [57] aimed to investigate the potential of gamification to promote the knowledge retention. The study results indicated that gamification produces a positive impact on knowledge retention and increases students' learning performances. In [75], Çakıroğlu et al. analyzed the effects of incorporating gamification in an Information and Communication Technology course. The findings of the study noticed that using game elements provides a positive impact on the student's motivation and engagement and indirectly influences the academic achievements. Moreover, the authors of [76] developed an Academic English game to study the effects of real competition and virtual competition on student learning. The outcomes of a real experiment showed that the student performances with the virtual competition were greatly better compared to real competition. Moreover, the time spent for undertaking the practical tasks was lower for students with virtual competition, and the learning behavior of those students improved. The experiment presented in [53] aimed to examine the impact of digital achievements on learners' motivations and performances, and the results showed an improvement of the students' motivations and performances. Furthermore, the findings revealed that the digital achievement efficiency was greatly dependent on the gamification strategy design. The authors proposed using a small amount of digital achievements with raised complexity.

Finally, Refs. [77,78] presented systematic mappings focused on the application of gamification in software engineering education. On the one hand, the review presented in [78] noted that most primary studies focus on promoting engagement and entertainment to keep students motivated. On the other hand, the aim of [77] was to identify the software engineering processes in which gamification was most frequently implemented. The review outcomes indicated that most primary studies applied gamification to provide training in the software development process. Besides, this review also analyzed several works describing practitioners' training experiences in software engineering best practices using gamification elements.

The papers previously analyzed clearly conclude that gamification is widely used for process improvements and learning initiatives, since it helps to drive people's behaviors, motivate and engage participants and, therefore, increase their performances. To analyze whether the benefits of gamification have been applied in the ITSM context, to what extent and with what results, we developed this systematic mapping study. Before undertaking our work, we examined the most frequently used digital databases to locate existing literature reviews that could examine this same topic. We conducted automatic searches in Scopus, Web of Science, Science Direct, IEEE Xplore, SpringerLink and the ACM Digital Library. The search string used was "(A1 OR A2) AND (B1 OR B2 OR B3) AND (C1 OR C2 OR C3 OR C4 OR C5 OR C6 OR C7 OR C8)". Table 1 shows the terms of this search string. The searches did not return any systematic literature review or systematic mapping focused on implementing gamification in ITSM processes. Thus, the work presented in this paper is the first literature review conducted in this area. 
Table 1. Search terms to identify related systematic reviews.

\begin{tabular}{lll}
\hline First Term & Second Term & Third Term \\
\hline & & C1. Systematic Review \\
& C2. Systematic Literature Review \\
A1. Gamif* & B2. IT service Management & C3. Research Review \\
A2. Funware & B3. ITIL & C4. Systematic Overview \\
& & C5. Systematic Mapping \\
& C6. Mapping Study \\
& C7. Systematic Mapping Study \\
& C8. Literature Survey \\
&
\end{tabular}

\section{Research Methodology}

With the purpose of analyzing and characterizing the state of research related to the gamification of ITSM processes and identifying challenges for future research, we carried out a systematic mapping following the recommendations of Peterson et al. [79]. This literature review was completed in four months (from September 2020 until December 2020) and covered all the publications in the area of ITSM processes gamification found so far.

\subsection{Research Questions}

Table 2 includes the research questions addressed in this study. The purpose is to analyze the use of gamification in initiatives of ITSM process implementations, describe the current status of this topic, and identify research opportunities.

Table 2. Research questions (RQ).

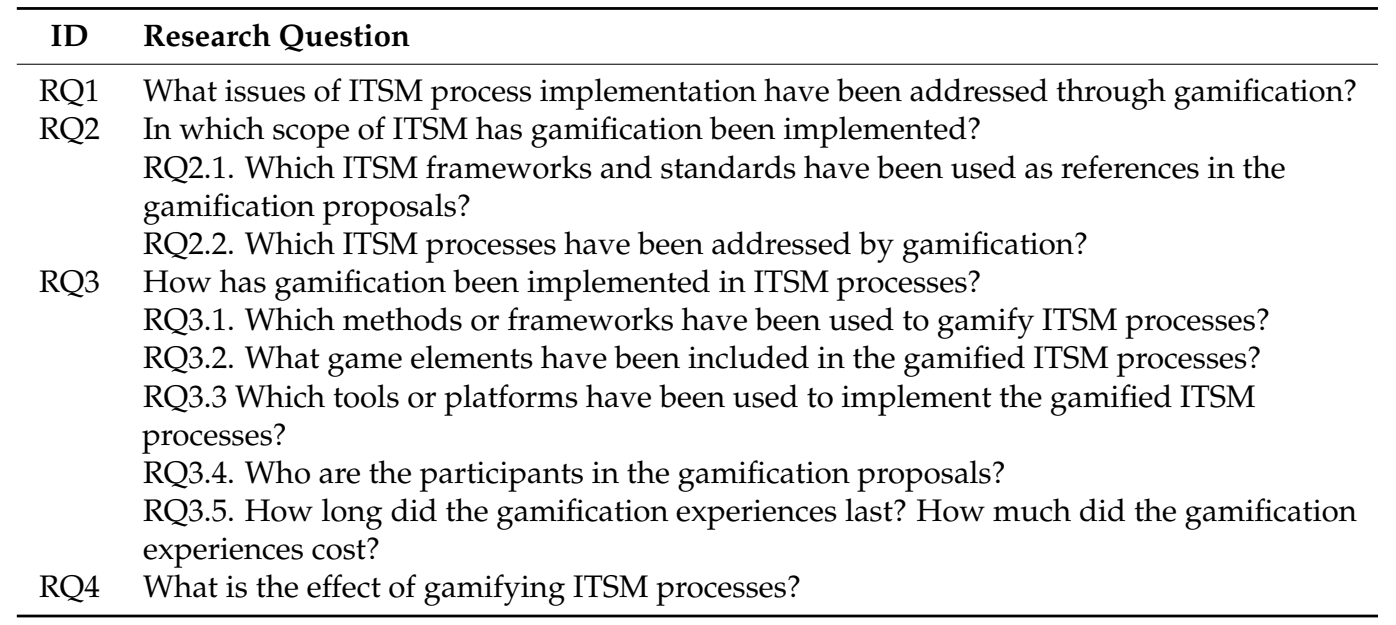

\subsection{Search Process}

To answer our research questions, we carried out a rigorous search to identify the primary studies. The search string consisted of the following Boolean expression: "(A1 OR A2) AND (B1 OR B2 OR B3 OR B4 OR B5 OR B6 OR B7)". Table 3 shows the terms of this search string. The two main terms of the search string are "Gamif*" ${ }^{* * \prime}$ means any text after "Gamif") and "IT service management". We also included the most relevant ITSM frameworks and standards. Most of the papers found in the searches performed with this search string apply gamification in the context of the IT service incident management. Thus, to achieve a more extensive coverage, we conducted additional searches with the search string: "(A1 OR A2) AND (C1 OR C2 OR C3 OR C4 OR C5 OR C6)" (see Table 3). Both search strings were applied on the Title, Abstract and Keywords. 
Table 3. Search terms to search the primary studies.

\begin{tabular}{lll}
\hline \multirow{2}{*}{ First Term } & \multicolumn{2}{c}{ Second Term } \\
\cline { 2 - 3 } & First Search & Second Search \\
\hline & B1. IT Service Management & C1. IT Service Incident \\
& B2. ITSM & C2. IT Service Incidence \\
A1. Gamif* & B3. IT Management & C3. IT Incident \\
A2. Funware & B4. ITIL & C4. IT Incidence \\
& B5. ISO 20000 & C5. Service Desk \\
& B6. ISO/IEC 20000 & C6. Help Desk \\
\hline
\end{tabular}

"' in "Gamif*" means any text after "Gamif".

The sources selected to identify the primary studies are shown in Table 4 (column "Primary sources"). To locate other relevant works, we also performed backward snowballing by tracing the reference list of the primary studies, forward snowballing by tracking the publications that reference the primary studies and scanning the works of the authors of the primary studies. For looking for the list of works of the primary studies' authors, we used the sources indicated in the column "Other sources". Table 5 offers an overview of the search results per database.

Table 4. Publication sources.

\begin{tabular}{cc}
\hline Primary Sources & Other Sources \\
\hline ACM Digital Library & Google Scholar \\
IEEE Xplore & ORCID \\
Science Direct & ResearchGate \\
SCOPUS & ResearchID \\
SpringerLink & SCOPUS authors details \\
Web of Science & \\
\hline
\end{tabular}

Table 5. Summary of search results.

\begin{tabular}{cc}
\hline Database & Search Results \\
\hline ACM Digital Library & 3 \\
IEEE Xplore & 11 \\
Science Direct & 67 \\
SCOPUS & 30 \\
SpringerLink & 74 \\
Web of Science & 14 \\
\hline
\end{tabular}

\subsection{Study Selection}

The works found during the search process were analyzed to determine their suitability for our study. The study selection process consisted of the following two phases:

Phase 1: Analyze the studies found during the search process in the primary sources and select the primary studies.

Phase 2: Examine the studies found performing backward snowballing and forward snowballing on the primary studies selected in the previous phase and the papers authored by the primary studies' authors. The relevant studies found in this phase are added to the list of primary studies.

The selection of the primary studies was done through two reviewing stages: (1) reading the titles and abstracts to decide possible significant works and (2) reading the conclusions or even the full text to resolve whether or not the study should be included as a primary study. We selected studies that introduced a theoretical or practical proposal to gamify ITSM processes and excluded the studies that complied with the exclusion criteria listed in Table 6. 
Table 6. Inclusion and exclusion criteria.

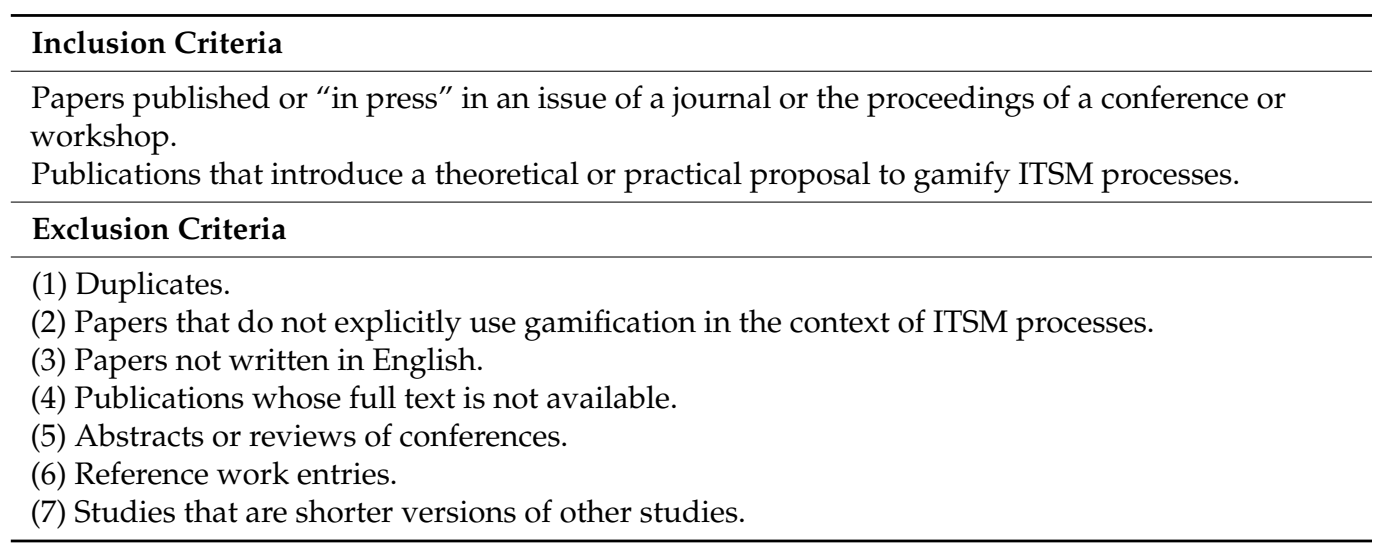

Table 7 provides an overview of the papers excluded for meeting any of the exclusion criteria. As a result, 14 papers found in the searches conducted in the primary sources were included as primary studies.

Table 7. Reason for paper exclusion.

\begin{tabular}{cc}
\hline Exclusion Criteria & Frequency \\
\hline$(1)$ & 41 \\
$(2)$ & 113 \\
$(3)$ & 23 \\
$(4)$ & 0 \\
$(5)$ & 6 \\
$(6)$ & 0 \\
$(7)$ & 2 \\
\hline
\end{tabular}

Figure 1 summarizes the process of the primary studies selection. No relevant publications were found conducting backward snowballing, forward snowballing and examining other papers of the primary authors. Appendix A contains the complete list of the primary studies.

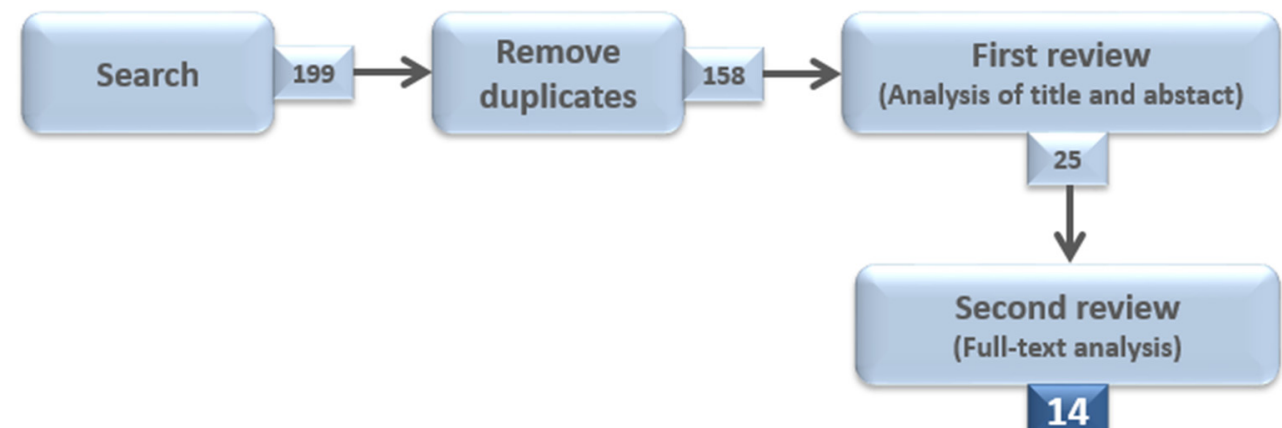

Primary studies

Figure 1. Process of primary studies selection.

\subsection{Data Extraction and Analysis}

A spreadsheet was designed to capture both the general data to identify the primary studies and the information necessary to answer the research questions addressed in our study (see Table 8). 
Table 8. Data extraction form.

\begin{tabular}{clc}
\hline Data Item & Value & RQ \\
\hline ID & Identifier of the paper. & \\
Title & Name of the paper. & \\
Authors & Name of all the paper's authors. & Year of publication. \\
Year & Name and quality of the publication place. & \\
Publication place & Opinion, personal experiences, philosophical, solution proposal, & \\
Research type & evaluation research and validation research [80]. & RQ1 \\
& Issues of ITSM process implementation addressed through & RQ2.1 \\
Issues & gamification. & RQ2.2 \\
Framework & ITSM reference model used in the study. & RQ3.1 \\
Process & ITSM processes gamified. & RQ3.2 \\
Methodology & Methodology or process followed to gamify ITSM processes. & RQ3.3 \\
Elements & Gamification elements included in the gamified ITSM processes. & RQ3.4 \\
Tools & Tools or technologies used to implement the gamification proposal. & RQ3.5 \\
Participants & Participated in the gamification experiences. & RQ4 \\
Duration/Cost & Duration and cost of the gamification experiences. & \\
Effect & Impact of gamifying ITSM processes. & \\
Notes & Any comment about the study that the authors want to record. & \\
\hline
\end{tabular}

\section{Results}

\subsection{General Results}

Table 9 includes the following data of the primary studies: identifier, publication year, publication and quality of the publication, according to the Journal Citation Reports (JCR) [81] for journal articles or the CORE ranking [82] for conference papers (the symbolwas used for publications that were not included in the JCR or CORE ranking). The results of analyzing the publication qualities showed that only two primary studies were published in high-quality conferences (CORE A). The rest of the publications were not indexed in the JCR or CORE rankings. It is noticeable that only $14 \%$ of the primary studies were published in high-quality publications. The rest of the primary studies were all published in low-quality ones. In our opinion, these data indicate that, despite the applicability of gamification in the context of ITSM processes, the research in this area is yet at an early stage.

Table 9. Publication year and publication quality of the primary studies.

\begin{tabular}{|c|c|c|c|}
\hline ID & Year & Publication & Quality \\
\hline [P01] & 2015 & $\begin{array}{l}\text { International Conference on Wireless and Telematics. } \\
\text { International Conference on Process Improvement and Capability }\end{array}$ & - \\
\hline [P02] & 2016 & $\begin{array}{l}\text { Determination in Software, Systems Engineering and Service } \\
\text { Management. }\end{array}$ & CORE A \\
\hline [P03] & 2014 & European Conference on Games-based Learning. & - \\
\hline [P04] & 2016 & Indonesian Journal of Electrical Engineering and Computer Science. & - \\
\hline [P05] & 2015 & International Conference on Wireless and Telematics. & - \\
\hline [P06] & 2014 & International Conference on Computer Supported Education. & - \\
\hline$[\mathrm{P} 07]$ & 2015 & $\begin{array}{l}\text { International Conference on HCI in Business. } \\
\text { International Conference on Process Improvement and Capability }\end{array}$ & - \\
\hline [P08] & 2017 & $\begin{array}{l}\text { Determination in Software, Systems Engineering and Service } \\
\text { Management. }\end{array}$ & CORE A \\
\hline [P09] & 2013 & $\begin{array}{l}\text { International Conference on Human-Computer Interaction, } \\
\text { Applications and Services. }\end{array}$ & - \\
\hline [P10] & 2016 & $\begin{array}{l}\text { International Conference on Human Interface and the Management of } \\
\text { Information. }\end{array}$ & - \\
\hline [P11] & 2017 & $\begin{array}{l}\text { International Conference on Electrical Engineering and Computer } \\
\text { Science. }\end{array}$ & - \\
\hline [P12] & 2018 & International Journal on Performance Improvement Quarterly. & - \\
\hline [P13] & 2014 & $\begin{array}{l}\text { International Conference on the Quality of Information and } \\
\text { Communications Technology. }\end{array}$ & - \\
\hline [P14] & 2015 & International Conference on Games and Learning Alliance. & - \\
\hline
\end{tabular}


Figure 2 shows the number of primary studies by publication year. The first study that applied gamification in ITSM processes dates back to 2013, and this study was the only one published that year. The amount of published studies increased in 2014, reaching four. However, this number decreased in 2015 to only two studies, growing up to four in 2016, the largest number of studies published in a single year. After 2016, the figure shows again a declining trend. In 2017, two works were published and one single one in 2018. We did not find any relevant study using gamification in any of the ITSM processes beyond 2018. Although it is difficult to infer a trend, since the time range of the data is short and there is fluctuation, it seems that interest in this topic has declined in recent years.

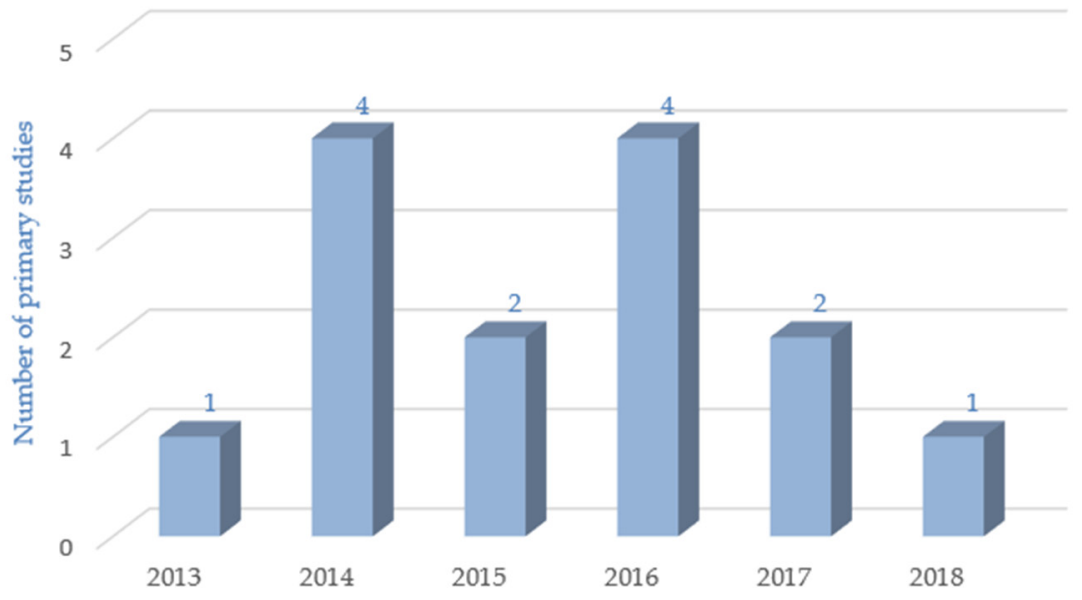

Figure 2. Number of primary studies by year.

Next, we answer the research questions addressed in this study.

\subsection{RQ1. What Issues of ITSM Process Implementation Have Been Addressed through} Gamification?

Analyzing the information obtained from the studies, we grouped the issues that these works deal with involving gamification into the four categories shown in Table 10. We only regarded the main issues referenced explicitly by the authors, without inferring any of them.

Table 10. Issues addressed by gamification in the primary studies. KPI: key performance indicators.

\begin{tabular}{|c|c|c|c|c|c|c|c|c|c|c|c|c|c|c|}
\hline Issue & [P01] & [P02] & [P03] & [P04] & [P05] & [P06] & [P07] & [P08] & [P09] & [P10] & [P11] & [P12] & [P13] & [P14] \\
\hline $\begin{array}{c}\text { Motivation and } \\
\text { engagement }\end{array}$ & $\mathrm{x}$ & $x$ & $\mathrm{x}$ & $x$ & $\mathrm{x}$ & $\mathrm{x}$ & $x$ & $\mathrm{x}$ & $x$ & $\mathrm{x}$ & $\mathrm{x}$ & $x$ & $\mathrm{x}$ & $\mathrm{x}$ \\
\hline Process learning & & & $x$ & & & $x$ & & & $x$ & & & $x$ & & $x$ \\
\hline Process KPIs & & & & $x$ & $x$ & $x$ & & & & & $x$ & & & \\
\hline User behavior & & $x$ & & & & & & $x$ & $x$ & & & & & \\
\hline
\end{tabular}

\section{(a) Motivation and Engagement}

As Figure 3 shows, we found that all the studies addressed the lack of motivation and engagement as one of the main issues in ITSM process implementation. On the one hand, the authors of [P02] considered that motivation and engagement of IT managers as key factors for the success of ITSM process implementation. They highlighted that gamification can help to address these issues, because IT managers engage and motivate in situations where the following conditions are met: (a) the objectives are clearly set, (b) there is a sense of progress, (c) the status is a consequence of meeting the objectives and (d) there are rewards for achieving the objectives. 


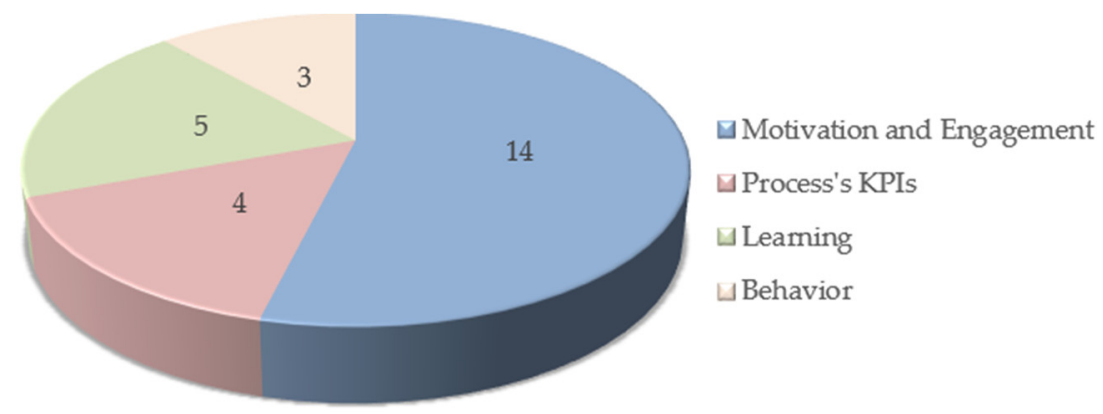

Figure 3. Number of primary studies by the issue they address. KPIs: key performance indicators.

On the other hand, other studies proposed the use of gamification to increase the motivation and engagement of employees of IT support organizations. These organizations are generally structured in several levels of support groups whose agents have to perform frequently monotonous and repetitive tasks. The authors of [P08] pointed out the idea that, by adopting gamification in service support processes, it is possible to include a factor of enthusiasm to the daily tasks of the agents and improve their motivations. Besides, agents ${ }^{\prime}$ engagement can increase, since their improvements are measurable, and agents' standings can enhance as a result of their job quality. Taking into account these ideas, the authors of [P08] designed a method to identify the most appropriate game elements to engage and motivate the agents involved in the incident management process. A similar perspective was presented in [P01] and [P05] by the authors. The research presented in [P01] focused on designing a gamified framework to improve the service support processes with fully engaged employees. The proposal in [P05] is a little more concrete, and the authors designed a gamified service desk prototype. In [P04], the framework proposed in [P01] was integrated with the user's motivation model described by Marczewski [83]. The result was an instrument that helps select which game elements to add into a gamified service desk to improve the agents' engagement. Likewise, in [P12], the same authors aimed to demonstrate that their proposal for gamifying a service desk. [P04] helps to improve the agents' motivations and engagement. In [P07], Yuan et al. also focused on the critical role of service desk agents, and they highlighted the importance of increasing their motivation to enhance the quantity and quality of the incident additional comments recorded in the knowledge database. They designed a gamification strategy to meet this objective and implemented such a strategy in the HP Service Manager tool [84]. The experiment results show the positive impact that the gamification strategy has on the improvement of the knowledge database contributions. Chunpir [P10] introduced the User Support-Worker's Activity Model (USWAM), a model to visualize and manage incidents that incorporates a point count system connected with a reward system to improve the interactivity of the employees of cyber infrastructures with the incidents. He also summarized a case study in the field of climate science cyber infrastructure [85] that shows the utility of the model to motivate the workers of a climate cyber infrastructure support. As the previous works, [P13] also highlighted the importance of motivating and involving service desk operators in their tasks for improving service quality. The authors offered a general vision about how gamification could positively influence those aspects. Finally, Sampanes [P09] stressed the usefulness of gamifying the actions of both agents and customers of service desks. In addition to motivating service desk agents, gamification could encourage service desk customers to collaborate and help each other to resolve their issues.

\section{(b) Process Learning}

The aim of [P03,P06,P09,P12,P14] was to improve the learning of the ITSM processes through gamification. On the one hand, Sillaots [P03] presented a proposal to gamify a master course of Research Methods for Educational Technology and IT Management. The objective of the designed gamification strategy was to make the course more engaging 
and help students achieve flow conditions (balance, clear goals, feedback, autonomy and immersion) [86]. The authors proposed including in the course a series of gamified learning activities (e.g., quiz) to trigger intrinsic motivation, and different gamification components (e.g., scoreboard) to generate extrinsic motivation. In [P14], Sillaots added the avatar game element in the gamified course presented in [P03]. He concluded that introducing avatars on the course did not influence on the students' motivation and satisfaction.

On the other hand, references [P09,P12] proposed adopting gamification in IT service support processes training. In [P09], Sampanes considered that the first field to adopt gamification into the internal support processes should be training of support engineers. He emphasized the idea that including gamification strategies in support processes training can help to (a) motivate engineers to improve their performance, (b) maintain engineers engaged during the training and (c) track their progress. While Sampanes did not propose any specific gamification strategy in [P09], Miller et al. [P12] did present one to increase the motivation of service desk employees towards their learning process and to provide a more thorough learning experience.

Finally, Brito et al. [P06] introduced a game-based learning approach for IT service transition. The authors concluded that using gamification in training sessions for the service transition team helps workers to acquire the necessary motivation and engagement for a successfully learning of IT service transition processes. The results of the application case presented showed that the service transition team learned and operated faster and more efficiently with the gamified training sessions.

\section{(c) Key Performance Indicators (KPIs) of Process}

As Table 10 indicates, four primary studies, references [P04,P05,P06,P11], remarked on the importance of analyzing the impact that gamifying ITSM processes has on process KPIs. Surendro and Raflesia [P04,P05,P11] studied the effects that adopting gamification in IT service desks can have on the KPIs of the incident management process. Though the authors proposed to evaluate the effects of gamification on several KPIs (response time, call rate, records of call request, incident handling rate, first call completion rate, etc.), in the study cases presented in references [P04,P11], they only evaluated the incident response time. On the other hand, Brito et al. [P06] highlighted that gamifying the learning of IT service transition processes can have some positive impact not only on employee's motivation but also on the process KPIs. Evaluation results indicated that the average deployment process time decreased in four months.

\section{(d) User Behavior}

Another important use of gamification is to drive the behavior of the gamified system users to meet established objectives. The proposal presented in [P02] focused on adopting gamification in the experimentation activity of process simulation models to foster in IT managers the necessary abilities to carry out satisfactorily process model simulations that allow them to make better decisions for enhancing the processes. On the other hand, in [P08] the authors highlighted that the adoption of an appropriate gamification strategy promotes that the incident management process's agents conduct the necessary actions to solve the incidents. Likewise, Sampanes [P09] noted the usefulness of gamification to encourage customers and IT support engineers to generate useful support documentation.

\subsection{RQ2. In Which Scope of ITSM Has Gamification Been Implemented?}

Next, we discuss the ITSM models used as reference in the gamification proposals as well as the gamified processes.

4.3.1. RQ2.1. Which ITSM Frameworks and Standards Have Been Used as References in the Gamification Proposals?

We found that ITIL was the only ITSM framework used as reference in the gamification proposals presented in the studies, and it was referenced in the $57 \%$ of the studies (eight 
papers): [P01,P02,P04,P05,P06,P08,P11,P13]. The remaining 43\% did not mention using any ITSM framework or standard. We think that ITIL is the only framework used as reference because ITIL is accepted as the facto standard for ITSM and is adopted by organizations worldwide [27].

\subsubsection{RQ2.2. Which ITSM Processes Have Been Addressed by Gamification?}

For each study, we collected its application domain and associated it with the most related ITSM process. Figure 4 shows the number of studies by the gamified ITSM processes and Table 11 displays the identifiers of the studies that present gamification proposals in the scope of each process. A description of these studies follows.

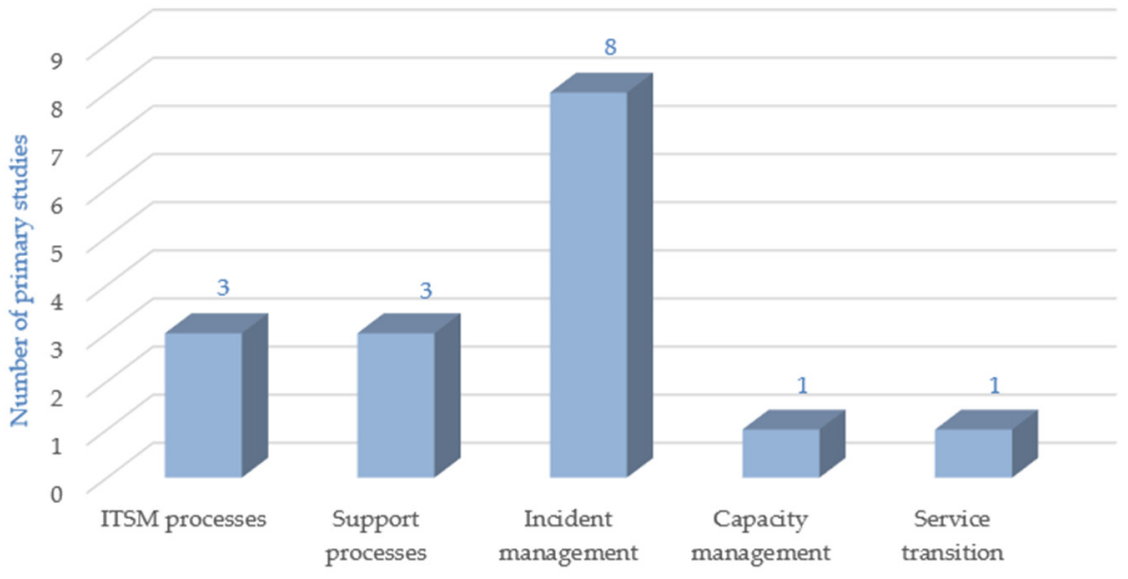

Figure 4. Number of primary studies by ITSM processes.

Table 11. Classification of the primary studies regarding the gamified ITSM processes.

\begin{tabular}{cc}
\hline ITSM Processes & Primary Studies \\
\hline No specific process & {$[\mathrm{P02}][\mathrm{P03}][\mathrm{P} 14]$} \\
IT service support processes & {$[\mathrm{P01}][\mathrm{P04}][\mathrm{P09}]$} \\
IT service incident management process & {$[\mathrm{P} 04][\mathrm{P} 05][\mathrm{P} 07][\mathrm{P07}][\mathrm{P} 10][\mathrm{P} 11][\mathrm{P} 12][\mathrm{P} 13]$} \\
IT service capacity management process & {$[\mathrm{P02}]$} \\
IT service transition processes & {$[\mathrm{P06}]$} \\
\hline
\end{tabular}

\section{(a) No Specific Process}

We can observe that three studies presented gamification proposals in the context of ITSM without focusing on any specific process. In their conceptual framework, the authors of [P02] focus on introducing a general proposal for the improvement of any ITSM process through simulation modeling and gamification. Similarly, by adding gamification elements in a course about IT Management, the student's immersion in their learning process can be improved [P03, P14]. Therefore, in these works the focus is not on the particular ITSM process the student is learning, but on the overall learning of the different ITSM processes.

\section{(b) IT Service Support and IT Service Incident Management Processes}

Most studies that addressed concrete ITSM processes focused on IT service support processes. In this category, we included papers that introduced generic gamification proposals that were applicable to several IT service support processes and papers that gamify the IT service desk for improving the IT service incident management process. The first study developed in the context of IT service support processes [P01] provided a very broad study about the positive impact that implementing gamification could have on both service supports' agents and customers. However, the proposals introduced in [P09] and [P04] are more concrete. In [P09], Sampanes presented a conceptual framework for adopting 
gamification in IT service support processes. In [P04], Surendro and Raflesia introduced a method to integrate gamification in ITIL service support processes and developed a prototype for gamifying IT service desk. Besides, they used this prototype to gamify the IT service desk in a company in Indonesia for improving the IT service incident management process. Additionally, Raflesia et al. showed in [P11] more evidence of the positive impact that the service desk prototype they presented in [P04] has on the engagement of service desk agents. The work of Yuan et al. [P07] also focused on using gamification in IT service desk. In concrete, the authors included gamification and persuasion mechanisms as incentives into the HP Service Manager product [84], a cloud-based help desk solution that helps companies manage the IT service incident management process. The main goal of [P07] was improving the performance of IT service desk agents and motivating them to deliver constantly good quality services. It aimed to motivate the agents of IT service desk to generate, share and improve the knowledge articles in the knowledge database. Conceicao et al. [P13] analyzed the use of gamification in IT service desk to improve the service incident management process. Likewise, the gamification proposals presented in [P05,P08,P10] aimed also to improve the IT service incident management process. Brito et al. [P05] presented a prototype of a web-based service system for gamifying this process. In [P08], the authors introduced a method for gamifying the IT service incident management process of ITIL. The concrete goal of the gamification model introduced in [P10] was improving the interactivity of the agents of cyber-infrastructures with the incidents and the management of the tasks allocated to the agents. Lastly, [P12] focused on gamifying the IT service desk training to increase the motivation of service desk agents and provide a more thorough experience.

\section{(c) IT Service Capacity Management Process}

We have found a single study that introduced a gamification proposal in the context of IT service capacity management process [P02]. The authors of this work presented a conceptual framework for improving ITSM processes that use gamification in the experimentation activity of process simulation models. The application case developed in the context of the IT service capacity management process show that the framework helps service providers to decide what service capacity strategy implementing for improving the service response times and ensuring the service level objectives compliance.

\section{(d) IT Service Transition Processes}

The only study that dealt with IT service transition was [P06]. The objective of this work was to present and evaluate a gamification approach for learning IT service transition processes. The results of the application case carried out provided a preliminary evidence that mixing business process management and gamification can accelerate the learning process.

\subsection{RQ3. How Has Gamification Been Implemented in ITSM Processes?}

To answer this question, we dealt with the following four aspects: (a) the methods or approaches utilized in the studies to elaborate the gamification proposals (RQ3.1), (b) the game elements included in the processes (RQ3.2), (c) the tools developed or used to gamify the processes (RQ3.3) and (d) additional data about the implementation of the gamification proposals such as the participants involved and the cost and time of implementing the gamified processes (RQ3.4 and RQ3.5).

\subsubsection{RQ3.1. Which Methods or Frameworks Have Been Used to Gamify ITSM Processes?}

Given the importance of using a gamification method or framework to design and implement adequate gamification strategies that allow the objectives fulfillment, next we analyze those used in the primary studies.

Table 12 presents the studies that have suggested methods or frameworks to gamify 
ITSM processes. The papers that did not follow a concrete method for incorporating gamification in these processes do not provide information about this question and, thus, are not included in this table (nine papers). Additionally, Table 12 does not include [P04] and [P12], because they are evaluation studies of the method presented in [P01] and do not give additional information regarding RQ3.1.

Table 12. Summary of the data collected about the gamification methods used in the primary studies.

\begin{tabular}{|c|c|c|}
\hline ID & Method Description & Method Activities \\
\hline [P01] & $\begin{array}{l}\text { Conceptual framework to gamify ITSM support } \\
\text { processes that is a combination of ITIL and a } \\
\text { process gamification methodology designed by } \\
\text { the authors. }\end{array}$ & $\begin{array}{l}\text { Feasibility study, analysis, design, } \\
\text { testing, implementation, } \\
\text { monitoring and evaluation. }\end{array}$ \\
\hline [P02] & $\begin{array}{l}\text { Conceptual framework to improve ITSM } \\
\text { processes based on building a process simulation } \\
\text { model and gamifying the simulation model } \\
\text { experimentation. The authors also designed a } \\
\text { methodology for gamifying the activity of } \\
\text { simulation model experimentation. For this, they } \\
\text { used the gamification process designed by } \\
\text { Werbach and Hunter [32] as a guideline and } \\
\text { adapted it to their case. }\end{array}$ & $\begin{array}{l}\text { Determine business objectives, } \\
\text { delineate target behaviors, } \\
\text { describe users, devise activity } \\
\text { cycles, incorporate fun and } \\
\text { deployment appropriate tools. }\end{array}$ \\
\hline [P08] & $\begin{array}{l}\text { Method for gamifying the IT service incident } \\
\text { management process that the authors designed } \\
\text { adapting the gamification framework proposed } \\
\text { by Werbach and Hunter [32] to this context and } \\
\text { taking into account ITIL recommendations. }\end{array}$ & $\begin{array}{l}\text { Determine business objectives, } \\
\text { delineate target behaviors, } \\
\text { describe users, devise activity } \\
\text { cycles, incorporate fun and } \\
\text { deployment the appropriate tools. }\end{array}$ \\
\hline
\end{tabular}

Table 12 shows that only three works proposed a concrete method or framework to gamify ITSM processes. The details of how these gamification procedures were designed and applied show that they are sufficiently versatile to be adapted to the goals and processes of each company.

- [P01]: The authors proposed a method to gamify ITSM support processes that integrates ITIL [11] and a process gamification framework that the authors also designed. The first activity of the method is a Feasibility study whose purpose is to identify the benefits of gamifying support processes. Next, the activity of Analysis focuses on determining the actual state of the support processes and collecting the stakeholder's needs. The third activity, Design, aimed to identify and prepare the services, and to define the game elements that will be integrated in the support processes. The objective of the fourth one, Testing, is to ensure that the design complies with the requirements of the gamified process. Then, the activity of Implementation contains tasks to incorporate the game elements into the process, to perform tests of the gamified process, to configure the IT infrastructure, to make the user guide, and to perform a training workshop. Finally, the activity Monitoring and Evaluation focuses on ensuring support processes run properly, asking user's opinion, reviewing the feedback and conducting the gap analysis. In [P04], Raflesia and Kridanto applied the method they proposed in [P01] to develop a gamified service desk prototype. Besides, in [P04] and [P12] they presented application cases of that service desk prototype to illustrate the positive impact that gamifying the service desk has on the engagements of the service desk agents, the service quality and the success of ITIL support processes adoption.

- [P02]: The authors introduced a conceptual framework for the enhancement of ITSM processes based on simulation modeling and gamification. Unlike the method proposed in [P01], the conceptual framework presented in [P02] can be applied in the context of any ITSM process. The main activities of the conceptual framework are the next three: (1) to define the organization's process, (2) to build a process simulation model and (3) to gamify the simulation model experimentation, for which a 
methodology is also proposed [P02]. The authors used both ITIL recommendations and the gamification procedure proposed by Werbach and Hunter [32] as a guideline to design their framework. Next, we summarize the main steps of the proposed gamification methodology. The purpose of the first activity, Define business objectives, is to motivate IT managers for performing model simulations and addressing IT manager behaviors through model simulations. Then, the activity Determine target behaviors focuses on identifying the behaviors to promote in IT managers (e.g., carry out model simulations by varying the process configurations) and defining adequate metrics to evaluate these behaviors (e.g., amount of model simulations conducted with diverse process configurations). The aim of the third activity, Design activity cycles, is to define the actions and simulations that IT managers would have to perform (e.g., perform model simulations with an initial process configuration) and to group them into progression levels (four levels). Next, to make the gamified system more fun (activity Incorporate fun) the authors proposed to include a game to find a treasure into the activity of simulation model experimentation. The last activity, Deploy appropriate tools, is centered on determining the game elements to include in the model simulations and to implement them. [P02] also presented an application case of the proposed conceptual framework for improving the ITIL capacity management process.

- [P08]: The authors of [P02] presented in [P08] a method for gamifying the IT service incident management that was designed considering ITIL recommendations and adapting the gamification framework proposed by Werbach and Hunter [32] to the particularities of this process. The first activity consists of identifying the incident management problems to address through gamification. The authors propose to identify the objectives to meet and the critical factors for the success of the incident management process (CSFs) (e.g., resolve the incidents as quickly as possible). Likewise, KPIs associated to the CSFs will be defined (e.g., average incident resolution time and amount/percentage of incidents resolved remotely). The following activity consists of determining the behaviors of the support group agents (e.g., to record new incidents, to determine the category and percentage of the incident, and to resolve the incident within response times set). The purpose of the third activity is to characterize the agents of the support groups (users of the gamified system in this case). The authors suggest interviewing support group agents, and to observe and measure their actual behaviors to identify their needs and motivations, and to determine their behavior in the process. After that, engagement loops will be defined to conduct the actions of the support group agents through the process. The main objective of this step is that support group agents manage adequately the incidents to fulfill the agreed service level agreements. Finally, to make the job of support group agents more enjoyable, the most adequate game elements will be selected and implemented in an incident management tool. To illustrate the utility and applicability of the gamification method proposed, [P08] presented an example of use to gamify the IT service incident management process in a hypothetical company.

As can be seen, the results of our study show that most studies implemented gamification in the area of ITSM processes by adopting some gamification ideas learned from literature or experimenting with game elements. Only three studies presented structured methods to design and implement adequate gamification strategies. This indicates the absence of a standardized method that details the concrete actions and steps to be carried out for gamifying ITSM processes.

\subsubsection{RQ3.2. What Game Elements Have Been Included in the Gamified ITSM Processes?}

Table 13 summarizes the game elements that the authors of the studies included in their gamification proposals and experiences. We have only considered the game elements referred explicitly by the authors without deducing any information. We would like to make it clear that we have included in Table 13 all the game elements cited regardless the level of detail and quality of the gamification proposal presented. [P11] has not been included 
in Table 13 because it is an evaluation study of the conceptual framework for gamifying service desks presented in [P04] and does not offer additional information about RQ3.2. We have followed the hierarchy defined by Werbach and Hunter [32] that include three types of elements labeled dynamics, mechanics and components. Game dynamics are the most abstract game elements that are associated to the human requirements and challenges that motivate people intrinsically (e.g., emotions, progression and relationships). Game mechanics are the basic actions that motivate and engage people, and drive their behavior through reward systems (e.g., feedback and competition). Finally, game components are the particular instantiations of game dynamics and mechanics (e.g., points, badges and leaderboard).

Table 13. Game elements included in the primary studies.

\begin{tabular}{|c|c|c|c|c|c|c|c|c|c|c|c|c|c|}
\hline Game Elements & [P01] & [P02] & [P03] & [P04] & [P05] & [P06] & [P07] & [P08] & [P09] & [P10] & [P12] & [P13] & [P14] \\
\hline \multicolumn{14}{|l|}{ Game dynamics } \\
\hline Emotions & & $X$ & & & & & & $X$ & & & & & \\
\hline Narrative & & & & & & & & & & & $X$ & & \\
\hline Progression & & $x$ & & & & & $x$ & $X$ & & & & & \\
\hline Relationships & & $X$ & & & & & & & & & & & \\
\hline Total & 0 & 3 & 0 & 0 & 0 & 0 & 1 & 2 & 0 & 0 & 1 & 0 & 0 \\
\hline \multicolumn{14}{|l|}{ Game mechanics } \\
\hline Competition & & & $X$ & & $X$ & & $X$ & & $X$ & & & & \\
\hline Collaboration & & & $X$ & & & & $x$ & & & & & & \\
\hline Socialization & & & & & & & $X$ & & & & $X$ & & \\
\hline Recognition & & & & & & & $X$ & & $X$ & & & & \\
\hline Feedback & & $x$ & $X$ & & & & $X$ & $\mathrm{X}$ & $X$ & $\mathrm{X}$ & & & \\
\hline Challenges & & $X$ & & & & & & $X$ & & $X$ & $X$ & & $X$ \\
\hline Chance & & $X$ & & & & & & $x$ & & & & & \\
\hline Rewards & & $x$ & & $X$ & & & $x$ & & & $x$ & $X$ & & \\
\hline Win states & & $X$ & & & & & & $X$ & & & & & \\
\hline Reinforcement & & & & & & & $X$ & & & & & & \\
\hline Sharing & & & & & & & $x$ & & & & & & \\
\hline Status & & & & $X$ & & & & & & $X$ & & & \\
\hline Total & 0 & 5 & 3 & 2 & 1 & 0 & 8 & 4 & 3 & 4 & 3 & 0 & 1 \\
\hline \multicolumn{14}{|l|}{ Game components } \\
\hline Avatars & & & $x$ & & & & & & & & & & \\
\hline Achievements & & $X$ & & & & & $X$ & & & & $X$ & $X$ & \\
\hline Virtual goods & & & & $X$ & & & & & & & & & \\
\hline Points & $X$ & $X$ & $X$ & $X$ & $X$ & $X$ & $X$ & $X$ & $X$ & $X$ & $X$ & & $X$ \\
\hline Badges & & $x$ & & $x$ & & $x$ & $X$ & $\mathrm{X}$ & $X$ & & & & $X$ \\
\hline Trophies & & $X$ & & & & & & $X$ & & & & & \\
\hline Stars & & $x$ & & & & & & & & & & & \\
\hline Quests & & & & $X$ & & & & & & & & & \\
\hline Bonus & & & & & & & & & & & $X$ & & \\
\hline Win prizes & & & & & & & $X$ & & & & & & \\
\hline Exclusive contents & & & & $x$ & & & & & & & & & \\
\hline Unlockable contents & & & & $X$ & & & & & & & & & \\
\hline Levels & & $\mathrm{X}$ & $X$ & $X$ & & $X$ & $X$ & & $X$ & $X$ & $x$ & & $X$ \\
\hline Rankings & & & & & & & $X$ & & & & $X$ & & $X$ \\
\hline Scoreboards & & & $x$ & & & & & & & & $x$ & & \\
\hline Leaderboards & & $x$ & & & $x$ & & $x$ & $x$ & $x$ & $x$ & $x$ & & \\
\hline Progress bars & & $X$ & & & & & $X$ & $X$ & & & & & \\
\hline Total & 1 & 8 & 4 & 7 & 2 & 3 & 8 & 5 & 4 & 4 & 7 & 1 & 4 \\
\hline
\end{tabular}

\section{(a) Game Dynamics}

As shown in Table 13, only four studies mentioned concrete game dynamics. [P02] and [P08] are the works that made use of more game dynamics. Those two papers included Emotions, since the authors want to improve the engagement, motivation, competitiveness, sense of achievement, and the desire to obtain a good status of the gamified process users. The two studies above mentioned and [P07] also referenced Progression, because the adoption of gamification could boost the skills and performance of the users. Moreover, 
the authors of [P02] cited Relationships, because they want to promote the relations and communication between IT managers. Finally, the game dynamic Narrative was only used in [P12]. The gamification strategy designed in this paper included challenges kept together by a space exploration theme. It is noticeable that the studies that adopted Emotions in their gamification proposals also used Progression. Figure 5 shows the number of studies by game dynamics.

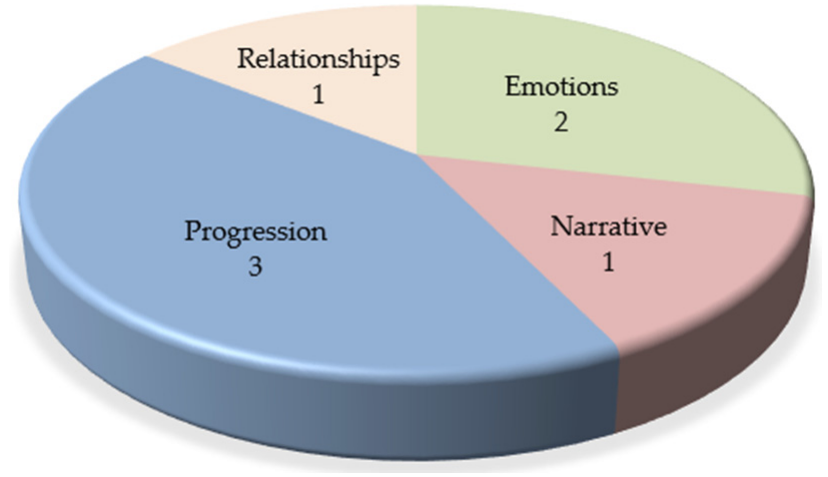

Figure 5. Number of primary studies by game dynamics.

\section{(b) Game Mechanics}

Regarding mechanics, Table 13 shows that [P07] is the study that included more game mechanics in the gamification proposal, followed by references [P02,P08,P10]. The rest of the studies used, at most, three game mechanics, except references [P01,P06,P13], which did not include any of them. Figure 6 summarizes the amount of papers that adopted each game mechanics. Rewards, Feedback and Challenges are the game mechanics most frequently referenced in the studies. Some of the papers, [P02,P08,P10], mentioned these three mechanics but others just some of them. The authors of these works proposed that the users of the gamified process receive positive rewards and feedback mainly when they complete their activities and tasks, and meet the objectives set. With respect Challenges, the level of detail that studies provided about the use of this mechanic is different in each work, [P14] just named this mechanic but the other papers afforded more information about the adoption of challenges. For example, [P08] incorporated challenges into the incident management process for improving the service desk agents' efficiency by conducting actions such as recording a new incident, establishing and registering incident's category and priority, and resolving the incident within the established times, among others. Conversely, the challenges considered in [P12] were the activities that service desk agents have to conduct through a learning system. Besides rewards, feedback and challenges, [P07] also incorporated Competition given that service desk agents can see their and other agent's levels on a leaderboard. Moreover, the gamification strategy proposed in [P07] also included Collaboration to promote that agents exchange knowledge for improving the quantity and quality of the incident tickets recorded in the knowledge database. On the other hand, the authors of [P02,P08] also incorporated in their gamification proposals Chance and Win States. On the one hand, the gamification strategy that the authors designed in [P02] comprised these elements because IT managers will get unexpected rewards during experimentation with process simulation models and will achieve win states when they meet the simulation objectives set. These mechanics are also employed in the gamification strategies proposed in [P08]. In this work, service desk agents would obtain unexpected rewards when their performance improves, and they would meet win states either when their performance enhanced greatly, or stood out from other agents'. The rest of game mechanics outlined in Table 13, Socialization, Recognition, Reinforcement, Sharing and Status, were used only in one or two studies and there is little information in the papers about how these mechanics were included in the processes. 


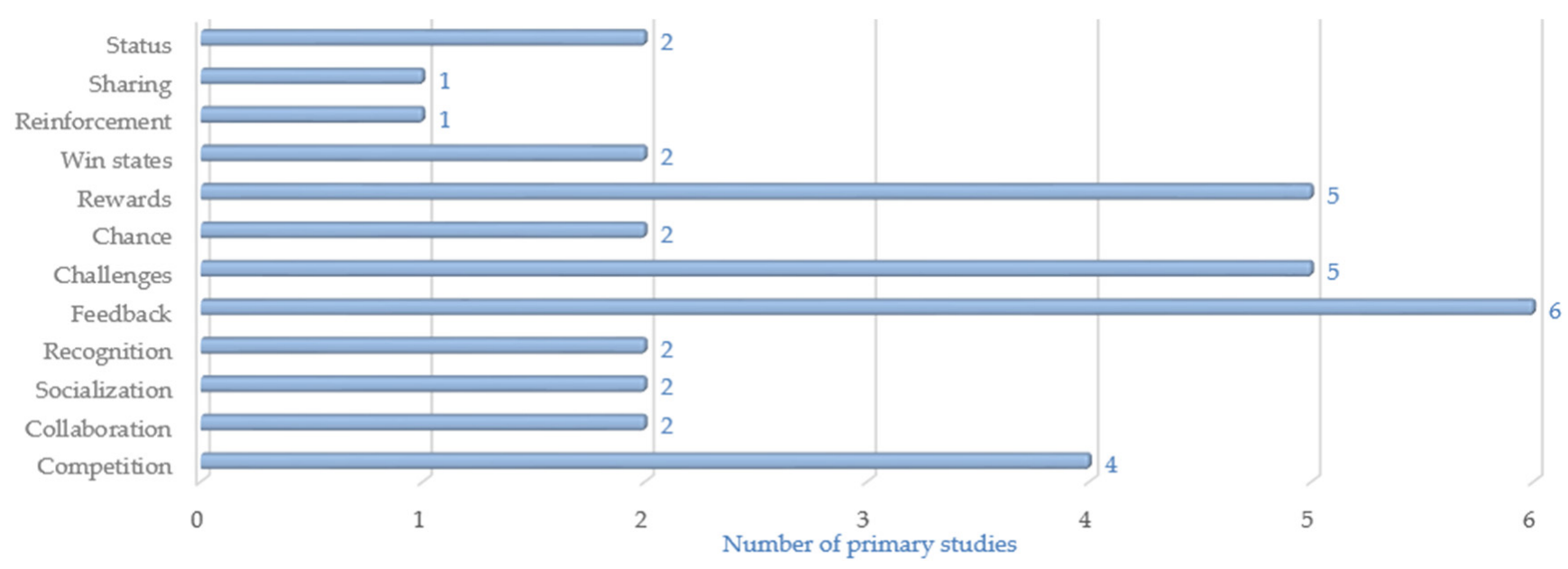

Figure 6. Number of primary studies by game mechanics.

\section{(c) Game Components}

In terms of game components Table 13 shows that references [P02,P04,P07,P12] are the studies that incorporated more game components in their gamification proposals (around seven or eight game components each). Then, references [P03,P08,P09,P10,P14] mentioned four or five game components each. The rest of the studies did not adopt more than three game components. Figure 7 summarizes the amount of papers that made use of each game component. Points were the most cited component. Around $92 \%$ of primary studies (13 papers) mentioned using them in their strategies. The users of the gamified systems obtain points when they perform any of their activities or tasks. For example, in reference [P08], support groups agents received points when they performed incident management activities such as to record a new incident, to resolve the incident within the agreed times, to escalate the incidents to the next support level or to close the incident record, among others. Badges, Levels and Leaderboards were the second most-frequently used game components. Between $46 \%$ and $54 \%$ of the studies (six/seven papers) implemented one or several of these game components in their gamification proposals. The authors of these papers proposed that users obtain Badges when they meet certain objectives. For example, in reference [P08], the agents of support groups got badges when the percentage of incidents that they resolved correctly improved by a target value and the percentage of incidents solved within the established times was equal or greater than an objective value. On the other hand, the use of Levels will enable to drive the behavior of the users through the gamified system, taking into account their progress. In reference [P02], for example, the purpose of the different levels was to learn conducting process model simulations, to perform process model simulations with an initial process configuration and to conduct simulations by varying the initial process configuration. Lastly, the adoption of Leaderboards in a gamified system would allow users to compare their progress and performance with those of other users. The rest of the game components outlined in Table 13 were mentioned in very few studies. 


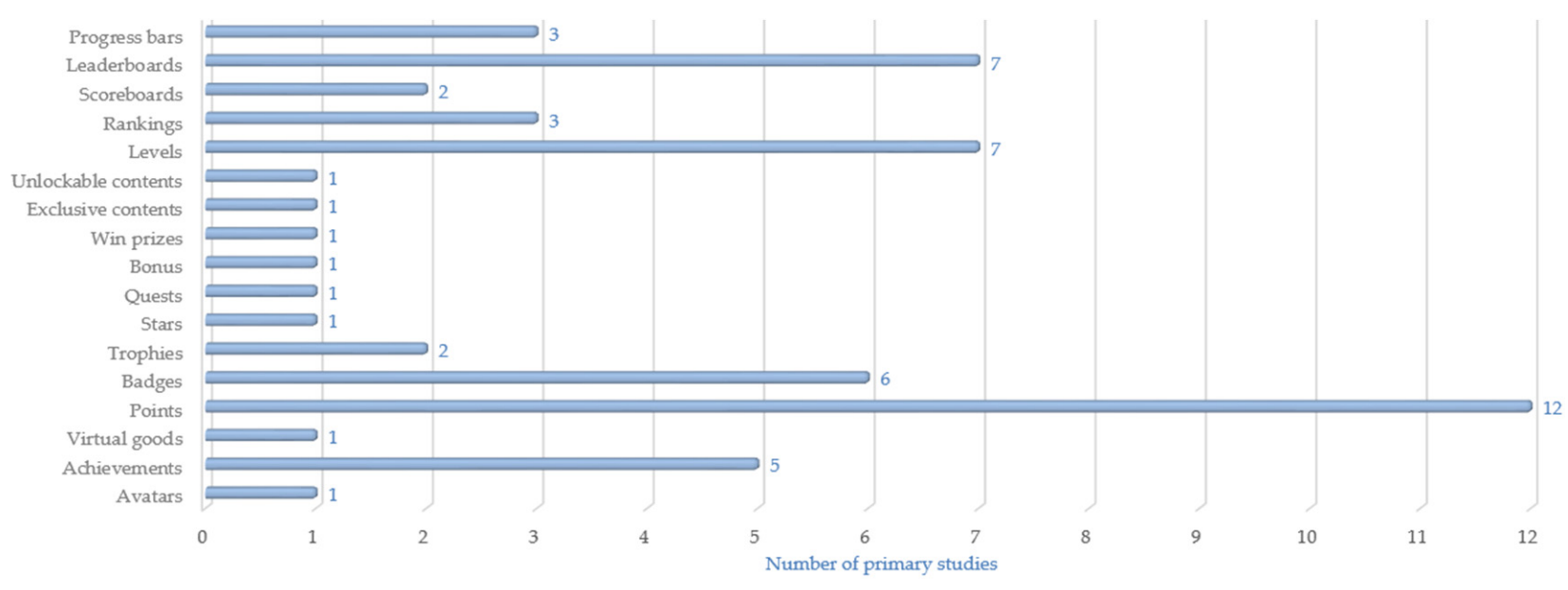

Figure 7. Number of primary studies by game components.

During the analysis of the studies to answer this $R Q$, we collected the game elements used to gamify ITSM processes. We noticed that not all the studies indicated clearly the approach followed to select the gamification elements and argued broadly the foundation behind using them. Likewise, many papers lack details about the manner in which the game elements were provided and how they were implemented. The articles that discussed more clearly the implementation of game elements in ITSM processes are $[\mathrm{P} 02, \mathrm{P} 04, \mathrm{P} 07, \mathrm{P} 08, \mathrm{P} 12]$. The other studies only mentioned the game elements or explained their use in very little detail.

\subsubsection{RQ3.3 What Tools or Platforms Have been Used to Implement the Gamified ITSM} Processes?

The analysis of studies shows that only three studies afforded some data regarding the technical implementation of the gamification strategies. In concrete, reference [P06] presented a gamified IT service transition learning system developed implementing game elements in an existing Business Process Management (BPM) tool (the authors did not indicate the specific gamified BPMN tool). The authors developed three new screens in a Python/Django system to register a new player, to define the badges and points rules, and to present the leaderboard. In reference [P07], the authors implemented some game elements and a persuasion mechanism as incentive in the HP Service Manager tool [84]. Finally, reference [P10] introduced a gamified system for supporting Earth System Gris Federation [87] that actually is under development. The system included a user support worker's activity tool to visualize and manage the incoming user incidents that incorporates a point count system to encourages support groups' agents to resolve the incidents.

\subsubsection{RQ3.4. Who are the Participants in the Gamification Proposals?}

Figure 8 summarizes the participants in the gamification strategies presented in the studies. As we previously saw in RQ2.2, most studies focused on gamifying an IT service support process. Thus, the users of the gamified systems are mainly the employees of IT companies that work in this process. In some studies, references [P01,P04,P05,P07,P08,P11, $\mathrm{P} 12, \mathrm{P} 13]$, the end users of the gamified systems are the agents of the service desk. In others, references [P09,P10], the users are the agents of all the support groups: service desk, first support level and second support level. Additionally, the authors of [P09] also noticed the importance of using gamification strategies to motivate and encourage customers to generate documentation useful for the support groups' agents. 


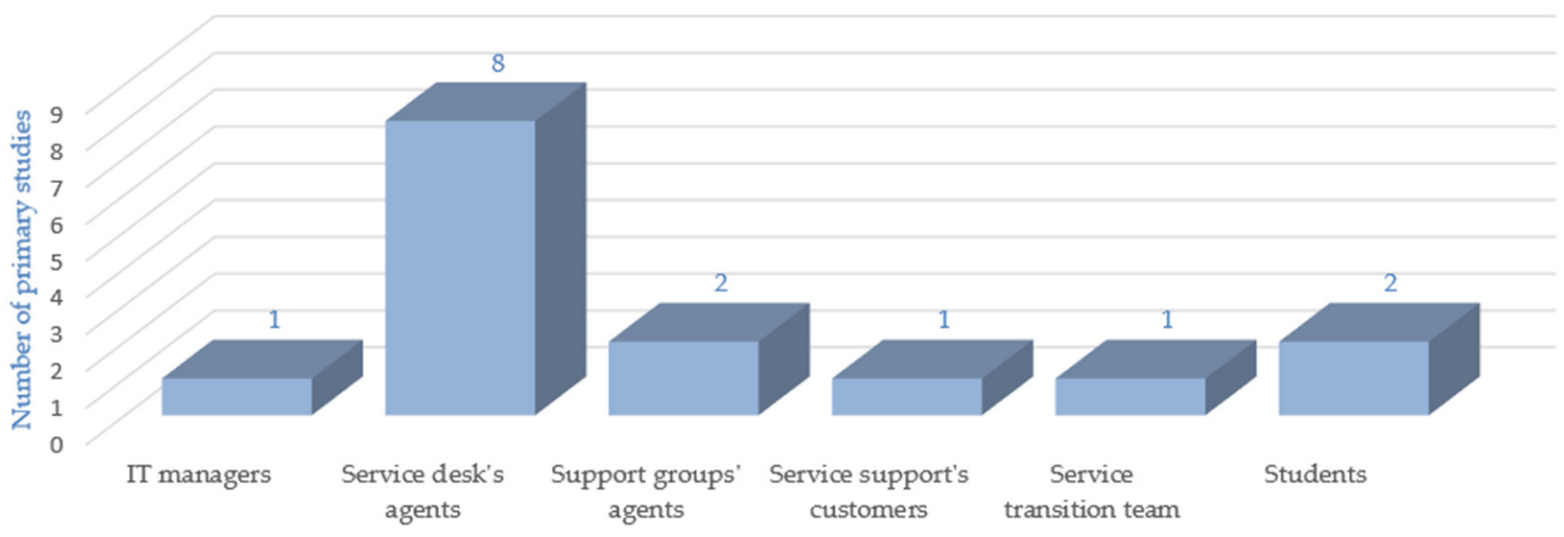

Figure 8. Number of primary studies by participants.

On the other hand, the users of the gamified systems proposed in the remaining studies are IT managers [P02], service transition team [P06] or the students of a course of research methods for educational technology and IT management [P03,P04].

4.4.5. RQ3.5. How Long Did the Gamification Experiences Last? How Much Did the Gamification Experiences Cost?

Table 14 shows the duration of the gamification experiences presented in the studies. The works that introduced theoretical gamification proposals and those that did not provide any information regarding the experience duration are not included in this table.

Table 14. Cost and duration of gamification experiences.

\begin{tabular}{cc}
\hline ID & Experience Duration \\
\hline$[\mathrm{P03}][\mathrm{P} 14]$ & 105 days \\
{$[\mathrm{P} 04]$} & 9 days \\
{$[\mathrm{P} 11]$} & 4 days \\
{$[\mathrm{P} 12]$} & 105 days \\
\hline
\end{tabular}

As Table 14 shows, references [P03,P04,P11,P12,P14] were the only studies that reported the duration of the gamification experiences. The gamified course about Research Methods of IT Management presented in references [P03,P14] took place during the autumn semester 2013 (15 weeks). In references [P12], the IT service desk agents made the test to validate the Space-Camp training module during the spring semester 2016 (15 weeks). On the other hand, the evaluation of the gamified service desk conducted in [P04] lasted approximately one week, and the test of the gamified service desk presented in reference [P11] around half week.

The only study that provided any information regarding the cost and time of incorporating gamification in an existing tool was references [P06]. The authors revealed that the total cost of incorporating game elements in a BPM tool for implementing a gamified IT service transition learning approach amounted to only 12 programmer hours. Regarding the time of implementing the game elements in the BPM tool, the authors indicated that seven months were needed to evolve the first version of the gamified software until the final version (first software version: 25th October 2012 and final software version: 17th May 2013).

The data that the studies offer regarding the gamification experiences indicate that experiences were only performed once, and their duration was quite short. Thus, the results obtained are not statistically significant and cannot be generalized. Therefore, their hypotheses cannot be considered proven. On the other hand, in order to evaluate the return of investment, it is necessary to estimate the cost of adopting gamification strategies and the benefits that IT companies would obtain gamifying ITSM processes. Only one of the 
studies analyzed [P06] indicated the development cost of the gamification tool utilized, though it seems too low for the development time reported by the authors. Likewise, the papers that presented gamification experiences do not provide any data about the cost of carrying out such experiences. Besides, none of the studies offered data regarding the economic benefits of adopting gamification in ITSM processes. Thus, in our opinion it is crucial to perform more empirical studies in the area, and collect more credible and generalized evidence for the ITSM community about the cost and the time needed to carry out gamification experiences.

\subsection{RQ4. What Is the Effect of Gamifying ITSM Processes?}

RQ4 aimed to look into the evidence reported in our primary studies about the impact of using gamification in the ITSM processes implementation. The information reported in the primary studies regarding the impact that gamification had on the experiences they describe is very variable. Several studies include highly theoretical gamification proposals and do not offer information about the impact their proposal has. Other studies do present evaluations of gamification experiences and report on this impact offering information that can be useful for ITSM practitioners. Table 15 outlines a summary of the reported effects of adopting gamification in ITSM processes. In this table, we classify each study according to the type of research conducted, the evaluation method followed to assess the results of the experience and the impact of gamification reported, if any.

Table 15. Summary of the gamification impact reported in the primary studies.

\begin{tabular}{|c|c|c|c|}
\hline ID & Research Type & $\begin{array}{l}\text { Evaluation } \\
\text { Method }\end{array}$ & Reported Gamification Impact \\
\hline [P01] & Philosophical & - None & - No impact reported. \\
\hline [P02] & Philosophical & - None & - No impact reported. \\
\hline [P03] & Evaluation & - Survey & $\begin{array}{l}\text { - Increased the engagement and } \\
\text { motivation of students in learning } \\
\text { activities. } \\
\text { - Aspects such as balance, } \\
\text { concentration, clear goals, feedback, } \\
\text { autonomy and immersion were } \\
\text { successfully achieved. }\end{array}$ \\
\hline [P04] & Evaluation & $\begin{array}{l}\text { - No method reported } \\
\text { - KPI evaluations }\end{array}$ & $\begin{array}{l}\text { - Improved the engagement and } \\
\text { motivation of service desk analysts, } \\
\text { and the values of User Engagement } \\
\text { Scale (UES) attributes. } \\
\text { - Improved KPIs (incident response } \\
\text { times) of incident management } \\
\text { process. }\end{array}$ \\
\hline [P05] & Philosophical & - None & - No impact reported. \\
\hline [P06] & Evaluation & $\begin{array}{l}\text { - Interview } \\
\text { - KPI evaluations }\end{array}$ & $\begin{array}{l}\text { - The gamified IT service transition } \\
\text { learning system helped the team to } \\
\text { speed up and materialize their } \\
\text { knowledge. } \\
\text { - Improved some KPIs of the IT } \\
\text { service transition processes. }\end{array}$ \\
\hline
\end{tabular}


Table 15. Cont.

\begin{tabular}{|c|c|c|c|}
\hline ID & Research Type & $\begin{array}{l}\text { Evaluation } \\
\text { Method }\end{array}$ & Reported Gamification Impact \\
\hline [P07] & Evaluation & - Interview & $\begin{array}{l}\text { - The motivation of the users of the } \\
\text { HP Service Manager product } \\
\text { improved. } \\
\text { Enhanced the quality of the incident } \\
\text { tickets that agents recorded in the } \\
\text { knowledge database. }\end{array}$ \\
\hline [P08] & Philosophical & - None & - No impact reported. \\
\hline [P09] & Opinion & - None & - No impact reported. \\
\hline [P10] & & - None & - No impact reported. \\
\hline [P11] & Evaluation & $\begin{array}{l}\text { - Interview } \\
\text { - KPI evaluations }\end{array}$ & $\begin{array}{l}\text { - Improved the engagement and } \\
\text { motivation of service desk agents. } \\
\text { - Improved the KPIs (incident } \\
\text { response time) of incident } \\
\text { management process. }\end{array}$ \\
\hline [P12] & Evaluation & - Survey & $\begin{array}{l}\text { - The gamified system for service } \\
\text { desk agents training is useful, } \\
\text { enjoyable and engaging. } \\
\text { - The gamified system had a positive } \\
\text { impact on some items of customer } \\
\text { satisfaction (response time, problem } \\
\text { solving and professional staff). }\end{array}$ \\
\hline [P13] & Evaluation & - Survey & $\begin{array}{l}\text { - Gamification had a positive impact } \\
\text { on service desk, but the survey } \\
\text { results also pointed out the need to } \\
\text { further improvement the motivation } \\
\text { and engagement of service desk's } \\
\text { agents. }\end{array}$ \\
\hline [P14] & Evaluation & - Survey & $\begin{array}{l}\text { The implementation of avatars in } \\
\text { the gamified course had no impact } \\
\text { on the motivation and engagement } \\
\text { of the students. }\end{array}$ \\
\hline
\end{tabular}

The following is a more detailed description of the impact reported in the papers that reported the impact that the use of gamification had on the ITSM processes.

- [P03]: At the end of the gamified course of Research Methods for Educational Technology and IT Management, Sillaots collected the feedback from the students through an online survey whose questions are expressed in a Likert Scale (values from 1 to 4 ). The survey results showed that gamifying the course influenced positively in students' engagement and motivation. The students indicated that it is easy concentrate on learning activities (average value: 3.49 ) and the learning activities are engaging (average value: 2.9). In reference [P14], Sillaots included avatars in the gamification strategy that he presented in [P03] to gamify the course. The results showed that using avatars did not have impact on the students' behavior during the learning activities and the students did not experiment a more thorough immersion. 
In reference [P14], Sillaots included avatars in the gamification strategy that he presented in [P03] to gamify the course. The results showed that using avatars did not have impact on the students' behavior during the learning activities and the students did not experiment a more thorough immersion.

- [P04]: Surendro and Raflesia evaluated their proposal for gamifying the incident management process through a study case. They used the User Engagement Scale (UES) introduced by Heather O'Brien [88] to evaluate the motivation and the engagement of the service desk analysts. The obtained results indicated that the UES attributes improved as follows: focused attention $(48 \%)$, aesthetic $(68 \%)$, novelty $(117 \%)$, perceived usability (39\%), endurability (38\%) and involvement (48\%). Likewise, the incident response time decreased in the gamified service desk between five and eight minutes. In [P11], Raflesia and Surendro evaluated their proposal for gamifying the service desk in another case study and they obtained similar results.

- [P06]: Brito et al. implemented their proposal for gamifying an IT service transition learning system in the case of a small team provided to migrate a mobile OS-based sales automation system in Brazil. The authors conducted a qualitative evaluation of the gamified system implementation by structured and open interviews implying all team members and corporate stakeholders. Besides, the authors also performed a quantitative analysis to evaluate the impact of the gamified approach on the deployment times. The results of this analysis indicated a significant reduction of the deployment time (approximately between two and eight months). On the other hand, though the authors concluded that the team was able to learn and operate faster and more effectively with the gamified system, they did not offer information about how they evaluated these aspects.

- [P07]: The results of the interviews conducted to the users of the gamified HP Service Manager product showed that most users were willing to record detailed information in incident tickets to help their peers. Besides, users were encouraged to contribute knowledge and to comment the incident articles when the data they registered was useful for other users. The interviewees noticed that the incorporation of gamification and the incentive system in the actual HP Service Manager product had a positive impact and the agents' motivation to perform their tasks greatly improved. In this paper, there is little evidence that gamification has positive effects because the authors have measured the impact considering only the qualitative data extracted from the interviews. Besides, they did not present in the paper the interviews data.

- [P12]: Qualitative feedback about the participants' experience in the gamified system for service desk training were collected through an anonymous online survey. The results indicated that the proposed training program was well-received by service desk agents. Most of participants (96\%) considered the training system funny and engaging. On the other hand, though the authors noticed that the gamified system has positive impact on the incident response time, they did not demonstrate that the incident response time decreases with the adoption of gamification.

- [P13]: Conceicao and Silva applied their gamification model for gamifying the service desk on a public IT service organization. They conducted an opinion survey to analyze the impact of gamification on the motivation and engagement of the service desk operators. With respect the motivation, the percentage of operators that responded each question value was "None" (0\%), "Little" (22\%), "Moderate" (22\%) and "Quite" $(56 \%)$. Concerning the engagement, the survey responses were "None" (0\%), "Little" (22\%), "Moderate" (22\%) and "Quite" (56\%).

The results of the gamification experiences reported in the primary studies can be useful for detecting the benefits and limitations of the gamification experiments carried out in ITSM, and reveal the positive impact that gamification can have in this field. This information can be useful for ITSM practitioners who plan to gamify their processes to anticipate the different effects of gamification and to highlight the lessons learned from previous experiences. However, given the very small number of published works that 
report on the empirical evaluation or validation of gamification experiences in the area of ITSM, the study of the impact of gamification included above cannot offer precise and conclusive findings. Besides, the scarce findings are hard to generalize given the small number of experiments conducted in a real organization setting. Consequently, no quantifiable impact on ITSM processes could be reported, impeding the assessment of the effect of gamification beyond the particular claims expressed by the authors in their papers. Furthermore, although the primary studies claim that gamifying ITSM processes had positive effects, in most of them the reported impact is only based on qualitative data obtained from interviews and surveys. Though qualitative data are useful to provide relevant information about the gamified experience, they are susceptible to subjectivity and should be combined with quantitative metrics to obtain more reliable data about the impact of gamification on the ITSM processes. Thus, it is necessary to conduct more empirical studies in this field and measure the impact of gamifying ITSM processes in a more comprehensive way using both qualitative data and quantitative metrics to obtain more reliable results.

\section{Threats to Validity}

The main threats to validity that should be considered in this review are the paper selection ways, imprecision in data extraction, and the incorrect classification. In order to overcome the impact of these constraints we used the guidelines of Petersen et al. [79] to define the review protocol.

We have made as much as possible to collect all the significant papers about this topic. Regarding the paper selection ways, we looked in six of the most relevant digital databases, covering journals, conferences and workshops. Besides, we performed backward and forward snowballing on the scientific primary studies, and examined the works of the authors of these studies. The process to select the papers to be included as primary studies in this review was a strict process in which the three authors participated. Though it is possible that some papers have been missed, we think that the search has been sufficiently rigorous and effective to ensure the completeness of our study.

The data extraction and paper classification were difficult mainly due to two factors. On the one hand, the lack of homogeneity of the terminology used for gamification design elements and a common classification scheme for such elements. On the other hand, the gamification proposals introduced in many of the primary studies were described with very little detail or the data to extract was not explicit in the papers, and we had to infer them. This may have resulted in some imprecisions in the data extraction and erroneous classifications. Despite this, the extraction and classification processes were rigorous as explained in Section 3. Besides, we consider that the participation in these processes of researchers with wide experience in gamification in ITSM scope and other areas reduced the risk of mistakes.

\section{Conclusions and Future Works}

The main objective of the systematic mapping presented in this paper is to analyze the current state of research in the scope of the ITSM processes gamification, and determine the main limitations and challenges in this research area.

The review results presented herein reveal that very little research has been carried out in this field until now. The research interest in gamifying the ITSM processes has been fluctuating since 2013 until 2018, and most of papers have been published in low quality publications (only $14 \%$ in high quality conferences, CORE A). Thus, it is clear that the adoption of gamification in the context of ITSM is in its early stages, and this entails a research opportunity for conducting rigorous comprehensive studies in this field.

The research papers we have analyzed highlight that implementing gamification in the ITSM processes can be useful mainly for the following aims:

- Motivating and engaging practitioners involved in the ITSM processes so that they can conduct their tasks more effectively. 
- Driving the behavior of the process's participants along the process and improving their performance.

- Increasing the commitment of practitioners in learning processes for enhancing their skills and competence.

- Improving the values of the process KPIs.

Regarding the ITSM processes in which gamification has been explored, it is noticeable that the IT service support processes are the processes most frequently gamified, especially the IT service incident management process. Most likely because that is the first process that IT organizations usually implement. Besides, the monotonous and repetitive nature of most of the tasks that support groups agents need to conduct makes of gamification an effective approach to address the agent's motivation in their daily tasks, and improving their performance. The lack of papers that implement gamification in the context of other ITSM processes opens an interesting opportunity for research and exploration.

Concerning the game elements included in the gamification proposals, we found that the game dynamics included were progression, emotions, relationship and narrative, though very few primary studies incorporated some of these dynamics. The mechanics most frequently incorporated were feedback, challenges, rewards and competition. The game components most commonly used were points, levels and leaderboard. Regarding the number of game components included in the gamification strategies, most primary studies named the ones they used, but did not explain clearly how they used them in their experiences. Those studies did not discuss the rationale behind the selection of such game components, neither did they address which of them were targeted to achieve which particular goal in the gamification experience. Besides, the authors ignored other relevant gamification design principles to meet the main aims of the gamification experience. Thus, the gamification schemas proposed in the papers analyzed are frequently too simple. Therefore, it is difficult to conclude which game components to select to promote the motivation and engagement in participants to achieve the objectives set. On the other hand, in most of the primary studies, the authors did not conduct a user profile analysis to determine the most adequate game elements to include in the gamification strategies depending on the characteristics of the distinct user types. Since not all people are motivated in the same way, it is important to analyze the different user types involved in the gamification experience, to identify the factors that motivate each user type and to design the most appropriate gamification strategy for each user type.

Other important conclusion of our review is that most of the primary studies adopted gamification simply applying some gamification ideas gained from literature or experiencing with game elements, and lack details about the concrete actions and steps taken to adopt gamification in the context of ITSM. Since the authors of these studies did not use any concrete gamification methodology, the gamification experiences conducted are immature and difficult to repeat in other contexts.

Finally, if we focus on the gamification experiments conducted in the primary studies, it is noticeable that few studies analyzed the effect of gamification through experiments in real IT organizations. Their results cannot be described as highly significant due to the small number of participants and the short duration of the experiences reported. The absence of empirical research methods to assess the effects of gamification in those experiences means that the results obtained so far do not allow any type of generalization since they are not statistically significant. The experiences described are also very particular to the organization that carries them out, making it hard to reproduce them in other organization or contexts. In addition, we could not find enough information about the cost and benefits of conducting the gamification experiences, so we cannot offer any conclusions regarding the return of the investment of using gamification in the ITSM processes. On the other hand, in most of the studies the positive, negative or no impact of gamification was measured considering only qualitative data using methods such as surveys or interviews. Therefore, there is very little evidence to justify the gamification impact beyond the statements made by the authors of the primary studies. Thus, to obtain more reliable data and measure 
the impact of gamification in a scientific manner, it is necessary to design and conduct quantitative research to collect metrics, allow repeatability, and perform formal statistical analysis of the data collected. This is an important challenge that can be addressed by:

- Gathering more data to generate more reliable results and conclusions about the gamification of the ITSM processes.

- Getting empirical evidence about the positive and negative effects of gamifying ITSM processes.

- Determining the particular effects of gamification on the different roles and user types involved in the ITSM processes.

- Identifying what ITSM process activities and practices are more adequate for gamification.

- Concluding which particular game elements incorporate in the gamification strategies to promote motivation and engagement of the process participants.

The development of the former activities opens new interesting research lines for researchers and practitioners interested in this topic. Figure 9 summarizes the state and limitations of the actual research in the field of ITSM gamification, and the main challenges identify that justify future research.

\begin{tabular}{|c|c|c|c|c|c|}
\hline \multicolumn{3}{|c|}{ CURRENT STATE } & \multicolumn{3}{|c|}{ LIMITATIONS } \\
\hline Publications & \multicolumn{2}{|c|}{$\begin{array}{l}\text { - } 14 \text { primary studies. } \\
\text { - Only two papers published in a high quality venue. } \\
\text { - Publication date between } 2013 \text { and } 2018 \text {. } \\
\text { - It is difficult to conclude a tendency. }\end{array}$} & Publications & \multicolumn{2}{|c|}{$\begin{array}{l}\text { - Few research papers published. } \\
\text { - Most of the papers published in low-impact publications. }\end{array}$} \\
\hline Issues & \multicolumn{2}{|l|}{$\begin{array}{l}\text { - Motivating and engaging process participants. } \\
\text { - Driving participant's behavior. } \\
\text { - Process participant's learning. } \\
\text { - Improving KPIs. }\end{array}$} & Issues & \multicolumn{2}{|c|}{ - Gamification can be used to address other issues. } \\
\hline $\begin{array}{c}\text { ITSM } \\
\text { Processess }\end{array}$ & \multicolumn{2}{|l|}{$\begin{array}{l}\text { - Mainly IT service support processes: } \\
\text { - IT service incident management. } \\
\text { - Service desk. }\end{array}$} & $\begin{array}{l}\text { ITSM } \\
\text { Processes }\end{array}$ & \multicolumn{2}{|c|}{$\begin{array}{l}\text { - Lack of papers that implement gamification in other } \\
\text { processes than the IT support processes. }\end{array}$} \\
\hline $\begin{array}{l}\text { Game } \\
\text { elements }\end{array}$ & \multicolumn{2}{|c|}{$\begin{array}{l}\text { Dynamics: Progression, Emotions. } \\
\text { - Mechanics: Feedback, Challenges, Rewards, Competition. } \\
\text { - Components: Points, Levels, Leaderboards. }\end{array}$} & $\begin{array}{l}\text { Game } \\
\text { elements }\end{array}$ & \multicolumn{2}{|c|}{$\begin{array}{l}\text { - Gamification designs frequently too simple. } \\
\text { - Analysis of the different user types not performed. }\end{array}$} \\
\hline Methodology & \multicolumn{2}{|c|}{$\begin{array}{l}\text { - Most studies apply some gamification ideas or experiment } \\
\text { with game elements. } \\
\text { - Only three works report using a gamification methodology. }\end{array}$} & Methodology & \multicolumn{2}{|c|}{$\begin{array}{l}\text { - Most studies do not design gamification. } \\
\text { - Missing information about the concrete actions and steps } \\
\text { taken to adopt gamification in the context of IISM. }\end{array}$} \\
\hline Experiments & \multicolumn{2}{|c|}{$\begin{array}{l}\text { - Few experiments in real organizations. } \\
\text { - Most of the results are unreliable due to lack of empirical } \\
\text { research. }\end{array}$} & Experiments & \multicolumn{2}{|c|}{$\begin{array}{l}\text { - Missing data about the cost and benefit of using gamification. } \\
\text { - Gamification impact is measured with qualitative data. } \\
\text { - Ex scientific evidence for the results of the experiments. }\end{array}$} \\
\hline \multicolumn{6}{|c|}{ RESEARCH CHALLENGES } \\
\hline \multicolumn{2}{|c|}{$\begin{array}{l}\text { Gamify other } \\
\text { processes }\end{array}$} & \multicolumn{3}{|c|}{$\begin{array}{l}\text { Establish the basis for selecting } \\
\text { the appropiate game elements for } \\
\text { the experience }\end{array}$} & $\begin{array}{l}\text { Design adequate gamification } \\
\text { strategies for each user type }\end{array}$ \\
\hline \multicolumn{2}{|c|}{$\begin{array}{l}\text { Use a gamification methodology to implement } \\
\text { adequate strategies in ITSM }\end{array}$} & \multicolumn{3}{|c|}{$\begin{array}{l}\text { Design and conduct quantitative } \\
\text { research to collect metrics }\end{array}$} & $\begin{array}{l}\text { Perform formal statistical } \\
\text { analysis of the data collected }\end{array}$ \\
\hline
\end{tabular}

Figure 9. Current state, limitations and research challenges of gamification in ITSM.

Finally, our future research works in the field of gamification in ITSM processes are as follows:

- Design a specific methodology for implementing systematic gamification in ITSM processes. Existing gamification methodologies could be adapted to the nature and characteristics that present such processes.

- Use the above-mentioned methodology to design gamification strategies for the improvement of different ITSM processes.

- Develop empirical research to obtain reliable results about the impact of gamification in ITSM processes. 
Author Contributions: Conceptualization, M.T., E.O. and M.R.; methodology, M.T., E.O. and M.R.; formal analysis, M.T., E.O. and M.R.; investigation, M.T. and E.O.; resources, M.R.; data curation, M.T. and E.O.; writing—original draft preparation, M.T. and E.O.; writing—review and editing, M.T., E.O. and M.R.; visualization, M.T. and E.O.; supervision, M.R.; project administration, M.R.; funding acquisition, M.R. All authors have read and agreed to the published version of the manuscript.

Funding: This work was funded by the Spanish National Research Agency (AEI) with FEDER funds under project EngageIT (PID2019-105455GB-C33), the network of excellence CALESI (TIN2017-90689REDT) and the Andalusian Plan for Research, Development, and Innovation (TIC-195).

Conflicts of Interest: The authors declare no conflict of interest.

\section{Appendix A. List of Primary Studies}

Table A1 contains the identifier and the reference of the primary studies of our systematic mapping study.

Table A1. Primary studies.

\begin{tabular}{|c|c|}
\hline ID & Reference \\
\hline [P01] & $\begin{array}{l}\text { Raflesia, Sarifah Putri, and Kridanto Surendro. 2016. "A Conceptual Framework for } \\
\text { Implementing Gamified-Service to Improve User Engagement by Using ITIL." in } \\
\text { Proceeding of } 2015 \text { 1st International Conference on Wireless and Telematics, ICWT } 2015 . \\
\text { Institute of Electrical and Electronics Engineers Inc. }\end{array}$ \\
\hline [P02] & $\begin{array}{l}\text { Orta, Elena, and Mercedes Ruiz. 2016. "A Simulation and Gamification Approach for It } \\
\text { Service Management Improvement." pp. 84-97 in Communications in Computer and } \\
\text { Information Science. Vol. 609. Springer Verlag. }\end{array}$ \\
\hline [P03] & $\begin{array}{l}\text { Sillaots, Martin. 2014. “Achieving Flow through Gamification: A Study on } \\
\text { Re-Designing Research Methods Courses.” Pp. 538-45 in Proceedings of the European } \\
\text { Conference on Games-based Learning. Vol. 2. }\end{array}$ \\
\hline [P04] & $\begin{array}{l}\text { Surendro, Kridanto, and Sarifah Putri Raflesia. 2016. “Designing Game-Based Service } \\
\text { Desk towards User Engagement Improvement." Indonesian Journal of Electrical } \\
\text { Engineering and Computer Science 1(2):381-89. doi: 10.11591/ijeecs.v1.i2.pp381-389. }\end{array}$ \\
\hline [P05] & $\begin{array}{l}\text { Raflesia, Sarifah Putri, and Kridanto Surendro. 2016. “Designing Gamified-Service } \\
\text { towards User Engagement and Service Quality Improvement." in Proceeding of the } 2015 \\
\text { 9th International Conference on Telecommunication Systems Services and Applications, TSSA } \\
\text { 2015. Institute of Electrical and Electronics Engineers Inc. }\end{array}$ \\
\hline [P06] & $\begin{array}{l}\text { Brito, Thiago Paiva, Josias Paes, and J. Antão B. Moura. 2014. "Game-Based Learning in } \\
\text { IT Service Transition: The Case of a Mobile Sales Service by a Small Team in Brazil." Pp. } \\
\text { 110-16 in CSEDU 2014_-Proceedings of the 6th International Conference on Computer } \\
\text { Supported Education. Vol. } 2 \text {. }\end{array}$ \\
\hline [P07] & $\begin{array}{l}\text { Yuan, Yue, Ke Ke Qi, and Aaron Marcus. 2015. "Gamification and Persuasion of HP IT } \\
\text { Service Management to Improve Performance and Engagement." Pp. 550-62 in Lecture } \\
\text { Notes in Computer Science (including subseries Lecture Notes in Artificial Intelligence and } \\
\text { Lecture Notes in Bioinformatics). Vol. 9191. Springer Verlag. }\end{array}$ \\
\hline [P08] & $\begin{array}{l}\text { Orta, Elena, Mercedes Ruiz, Alejandro Calderón, and Nuria Hurtado. } 2017 . \\
\text { “Gamification for Improving IT Service Incident Management.” pp. 371-83 in } \\
\text { Communications in Computer and Information Science. Vol. 770. Springer Verlag. }\end{array}$ \\
\hline [P09] & $\begin{array}{l}\text { Sampanes, Anthony Chad. 2013. “Gamifying Support.” Pp. 284-91 in Lecture Notes in } \\
\text { Computer Science (including subseries Lecture Notes in Artificial Intelligence and } \\
\text { Lecture Notes in Bioinformatics). Vol. } 8005 \text { LNCS. Springer, Berlin, Heidelberg. }\end{array}$ \\
\hline [P10] & $\begin{array}{l}\text { Chunpir, Hashim Iqbal. 2016. "Prioritizing Tasks Using User-Support-Worker's Activity } \\
\text { Model (USWAM)." Pp. 379-90 in Lecture Notes in Computer Science (including } \\
\text { subseries Lecture Notes in Artificial Intelligence and Lecture Notes in Bioinformatics). } \\
\text { Vol. 9735. Springer Verlag. }\end{array}$ \\
\hline
\end{tabular}


Table A1. Cont.

\begin{tabular}{|c|c|}
\hline ID & Reference \\
\hline [P11] & $\begin{array}{l}\text { Raflesia, Sarifah Putri, Kridanto Surendro, and Rossi Passarella. 2017. "The User } \\
\text { Engagement Impact along Information Technology of Infrastructure Library (ITIL) } \\
\text { Adoption." Pp. 184-87 in ICECOS 2017-Proceeding of } 2017 \text { International Conference on } \\
\text { Electrical Engineering and Computer Science: Sustaining the Cultural Heritage Toward the } \\
\text { Smart Environment for Better Future. }\end{array}$ \\
\hline [P12] & $\begin{array}{l}\text { Miller, Carrie Lewis, J. C. Grooms, and Hunter King. 2018. "To Infinity and } \\
\text { Beyond-Gamifying IT Service-Desk Training: A Case Study." Performance Improvement } \\
\text { Quarterly 31(3):249-68. doi: 10.1002/piq.21263. }\end{array}$ \\
\hline [P13] & $\begin{array}{l}\text { Conceicao, Fabio, Alan Silva, Ananias Filho, and Reinaldo Cabral. 2014. “Toward a } \\
\text { Gamification Model to Improve IT Service Management Quality on Service Desk." Pp. } \\
255-60 \text { in Proceedings-2014 9th International Conference on the Quality of Information and } \\
\text { Communications Technology, QUATIC 2014. Institute of Electrical and Electronics } \\
\text { Engineers Inc. }\end{array}$ \\
\hline [P14] & $\begin{array}{l}\text { Sillaots, Martin. 2015. “Using Avatars for Course Management and Immersion." Pp. } \\
163-73 \text { in Lecture Notes in Computer Science (including subseries Lecture Notes in Artificial } \\
\text { Intelligence and Lecture Notes in Bioinformatics). Vol. } 9221 . \text { Springer Verlag. }\end{array}$ \\
\hline
\end{tabular}

\section{References}

1. Mesquida, A.-L.; Mas, A.; Calafat, A.L.M. Integrating IT service management requirements into the organizational management system. Comput. Stand. Interfaces 2015, 37, 80-91. [CrossRef]

2. Tang, X.; Todo, Y. A Study of Service Desk Setup in Implementing IT Service Management in Enterprises. Technol. Investig. 2013, 4, 190-196. [CrossRef]

3. Wautelet, Y. A model-driven IT governance process based on the strategic impact evaluation of services. J. Syst. Softw. 2019, 149, 462-475. [CrossRef]

4. Young, C.M. An Introduction to IT Service Management; Research Note, COM-10-8287; Gartner: Stamford, CT, USA, 2004.

5. Conger, S.; Winniford, M.; Erickson-Harris, L. Service Management in Operations. 2008. Available online: https://aisel.aisnet. org/amcis2008/362 (accessed on 5 April 2021).

6. Mora, M.; Gomez, J.M.; O'Connor, R.V.; Raisinghani, M.; Gelman, O. An Extensive Review of IT Service Design in Seven International ITSM Processes Frameworks. Int. J. Inf. Technol. Syst. Approach 2015, 8, 69-90. [CrossRef]

7. Mora, M.; Raisinghani, M.; O'Connor, R.V.; Gomez, J.M.; Gelman, O. An Extensive Review of IT Service Design in Seven International ITSM Processes Frameworks. Int. J. Inf. Technol. Syst. Approach 2014, 7, 83-107. [CrossRef]

8. ISO/IEC. ISO_ISO/IEC 20000-1:2011—Information Technology—Service Management—Part 1: Service Management System Requirements. 2011. Available online: https://www.iso.org/standard/51986.html (accessed on 5 April 2021).

9. ISO/IEC. ISO_ISO/IEC 20000-2:2012—Information Technology—Service Management—Part 2: Guidance on the Application of Service Management Systems. 2012. Available online: https:/ /www.iso.org/standard/51987.html (accessed on 5 April 2021).

10. CMMI. CMMI ${ }^{\circledR}$ for Services, Version 1.3 CMMI Product Team Improving Processes for Providing Better Services. 2010. Available online: http:/ / www.sei.cmu.edu (accessed on 5 April 2021).

11. OGC. Information Technology Infraestructure Library (ITIL V4). 2019. Available online: https://www.itil.org.uk/ (accessed on 5 April 2021).

12. Marrone, M.; Kolbe, L.M. Impact of IT Service Management Frameworks on the IT Organization. Bus. Inf. Syst. Eng. 2011, 3, 5-18. [CrossRef]

13. Marrone, M.; Kolbe, L.M. Uncovering ITIL claims: IT executives' perception on benefits and Business-IT alignment. Inf. Syst. e-Bus. Manag. 2011, 9, 363-380. [CrossRef]

14. Mesquida, A.L.; Mas, A.; Amengual, E.; Calvo-Manzano, J.A. IT Service Management Process Improvement based on ISO/IEC 15504: A systematic review. Inf. Softw. Technol. 2012, 54, 239-247. [CrossRef]

15. Andrews, A.A.; Beaver, P.; Lucente, J. Towards better help desk planning: Predicting incidents and required effort. J. Syst. Softw. 2016, 117, 426-449. [CrossRef]

16. Cater-Steel, A.; Tan, W. Implementation of IT infrastructure library (ITIL) in Australia: Progress and success factors. In Proceedings of the IT Governance International Conference, Auckland, New Zealand, 14-16 November 2005.

17. Lepmets, M.; McBride, T.; Ras, E. Goal alignment in process improvement. J. Syst. Softw. 2012, 85, 1440-1452. [CrossRef]

18. Shrestha, A.; Cater-Steel, A.; Toleman, M.; Rout, T. Benefits and relevance of International Standards in a design science research project for process assessments. Comput. Stand. Interfaces 2018, 60, 48-56. [CrossRef] 
19. ISO/IEC. ISO_ISO/IEC TS 15504-8:2012—Information Technology_Process Assessment—Part 8: An Exemplar Process Assessment Model for IT Service Management. 2012. Available online: https:/ /www.iso.org/standard/50625.html (accessed on 5 April 2021).

20. TIPA. IT Process Assessment-TIPA for ITIL and IT Service Management. 2020. Available online: https://www.tipaonline.org/ (accessed on 5 April 2021).

21. Cruz-Hinojosa, N.J.; Gutiérrez-De-Mesa, J.A. Literature review of the situation research faces in the application of ITIL in Small and Medium Enterprises. Comput. Stand. Interfaces 2016, 48, 124-138. [CrossRef]

22. Jantti, M.; Rout, T.; Wen, L.; Heikkinen, S.; Cater-Steel, A. Exploring the Impact of IT Service Management Process Improvement Initiatives: A Case Study Approach. Program. Ing. Nat. 2013, 176-187. [CrossRef]

23. Melendez, K.; Dávila, A.; Pessoa, M. Information technology service management models applied to medium and small organizations: A systematic literature review. Comput. Stand. Interfaces 2016, 47, 120-127. [CrossRef]

24. Pollard, C.; Cater-Steel, A. Justifications, Strategies, and Critical Success Factors in Successful ITIL Implementations in U.S. and Australian Companies: An Exploratory Study. Inf. Syst. Manag. 2009, 26, 164-175. [CrossRef]

25. Eikebrokk, T.R.; Iden, J. Strategising IT service management through ITIL implementation: Model and empirical test. Total. Qual. Manag. Bus. Excel. 2015, 28, 238-265. [CrossRef]

26. Barafort, B.; Shrestha, A.; Cortina, S.; Renault, A. A software artefact to support standard-based process assessment: Evolution of the TIPA ${ }^{\circledR}$ framework in a design science research project. Comput. Stand. Interfaces 2018, 60, 37-47. [CrossRef]

27. Iden, J.; Eikebrokk, T.R. Implementing IT Service Management: A systematic literature review. Int. J. Inf. Manag. 2013, 33, 512-523. [CrossRef]

28. Korsaa, M.; Johansen, J.; Schweigert, T.; Vohwinkel, D.; Nevalainen, R. The people aspects in modern process improvement management approaches. J. Softw. Evol. Process. 2013, 25, 381-391. [CrossRef]

29. Gartner. Gartner Study; Cox, R., Marriot, I., Seabrook, D., Eds.; The Gartner Group: Stamford, CT, USA, 2003.

30. Ahmad, N.; Shamsudin, Z.M. Systematic Approach to Successful Implementation of ITIL. Procedia Comput. Sci. 2013, 17, 237-244. [CrossRef]

31. Schmidtbauer, P.; Sandkuhl, K.; Stamer, D. The Industrial Practice of ITIL Implementation in Medium-Sized Enterprises. Bus. Inf. Syst. 2013, 160, 124-135. [CrossRef]

32. Werbach, K.; Hunter, D. For the Win: How Game Thinking Can Revolutionize Your Business; Wharton Digital Press: Philadephia, PA, USA, 2012.

33. Seixas, L.D.R.; Gomes, A.S.; Filho, I.J.D.M. Effectiveness of gamification in the engagement of students. Comput. Hum. Behav. 2016, 58, 48-63. [CrossRef]

34. Deterding, S.; Dixon, D.; Khaled, R.; Nacke, L. From game design elements to gamefulness. In Proceedings of the 15th International Academic MindTrek Conference on Envisioning Future Media Environments-MindTrek '11; Association for Computing Machinery (ACM): New York, NY, USA, 2011; pp. 9-15.

35. Johnson, L.; Johnson, L.; Becker, S.A.; Cummins, M.; Estrada, V.; Freeman, A.; Hall, C. NMC Horizon Report: 2016 Higher Education Edition; The New Media Consortium: Austin, TX, USA, 2016.

36. Herranz, R.; Colomo-Palacios, A.; Seco, M.S.-G. Towards a Gamification Framework for Software Process Improvement Initiatives: Construction and Validation. J. Univers. Comput. Sci. 2016, 22, 1509-1532. Available online: http://www.jucs.org/jucs_22_12/ towards_a_gamification_framework (accessed on 5 April 2021).

37. Hsu, C.-L.; Chen, M.-C. How gamification marketing activities motivate desirable consumer behaviors: Focusing on the role of brand love. Comput. Hum. Behav. 2018, 88, 121-133. [CrossRef]

38. Rodrigues, L.F.; Oliveira, A.; Costa, C.J. Does ease-of-use contributes to the perception of enjoyment? A case of gamification in e-banking. Comput. Hum. Behav. 2016, 61, 114-126. [CrossRef]

39. González, C.S.; Gómez, N.; Navarro, V.; Cairós, M.; Quirce, C.; Toledo, P.; Marrero-Gordillo, N. Learning healthy lifestyles through active videogames, motor games and the gamification of educational activities. Comput. Hum. Behav. 2016, 55, 529-551. [CrossRef]

40. Indriasari, T.D.; Luxton-Reilly, A.; Denny, P. Gamification of student peer review in education: A systematic literature review. Educ. Inf. Technol. 2020, 25, 5205-5234. [CrossRef]

41. Alhammad, M.M.; Moreno, A.M. Challenges of gamification in software process improvement. J. Softw. Evol. Process. 2020, 32, e2231. [CrossRef]

42. Hosseini, C.; Haddara, M. Gamification in Enterprise Systems: A Literature Review. Adv. Hum. Factors Bus. Manag. Train. Educ. 2019, 1070, 552-562.

43. Orta, E.; Ruiz, M. A Simulation and Gamification Approach for IT Service Management Improvement. Adv. Serv. Oriented Cloud Comput. 2016, 609, 84-97. [CrossRef]

44. Orta, E.; Ruiz, M.; Calderón, A.; Hurtado, N. Gamification for Improving IT Service Incident Management. Relat. Datenbanken 2017, 770, 371-383. [CrossRef]

45. Webster, J.; Watson, R. Analyzing the past to prepare for the future: Writing a literature review. Manag. Inf. Syst. Q. 2002, 26, xiii-xxiii. Available online: https:/ /aisel.aisnet.org/misq/vol26/iss2/3 (accessed on 5 April 2021).

46. Blumberg, M.; Cater-Steel, A.; Rajaeian, M.M.; Soar, J. Effective organisational change to achieve successful ITIL implementation. J. Enterp. Inf. Manag. 2019, 32, 496-516. [CrossRef] 
47. Jantti, M.; Kallinen, H. Exploring service desk employees' motivation and rewarding. In Proceedings of the 2017 International Conference on Service Systems and Service Management, Dalian, China, 16-18 June 2017; pp. 1-6.

48. Raflesia, S.P.; Surendro, K.; Passarella, R. The user engagement impact along information technology of infrastructure library (ITIL) adoption. In Proceedings of the 2017 International Conference on Electrical Engineering and Computer Science (ICECOS), Palembang, Indonesia, 22-23 August 2017; pp. 184-187.

49. Santi, C.; Martí, C. Implementing Service Management Standards: Motivations and Key Factors. In ISO 9001, ISO 14001, and New Management Standards; Springer: Cham, Switzerland, 2018; pp. 83-96.

50. Vicente, M.; Gama, N.; Da Silva, M.M. A Business Motivation Model for IT Service Management. Int. J. Inf. Syst. Model. Des. 2014, 5, 83-107. [CrossRef]

51. Hamari, J.; Koivisto, J.; Sarsa, H. Does Gamification Work?-A Literature Review of Empirical Studies on Gamification. In Proceedings of the 47th Hawaii International Conference on System Sciences, Waikoloa, HI, USA, 6-9 January 2014.

52. Market\&Market. Gamification Market Worth $\$ 30.7$ Billion by 2025. 2020. Available online: https://www.marketsandmarkets. com/PressReleases/gamification.asp (accessed on 5 April 2021).

53. Groening, C.; Binnewies, C. "Achievement unlocked!"- The impact of digital achievements as a gamification element on motivation and performance. Comput. Hum. Behav. 2019, 97, 151-166. [CrossRef]

54. Koivisto, J.; Hamari, J. The rise of motivational information systems: A review of gamification research. Int. J. Inf. Manag. 2019, 45, 191-210. [CrossRef]

55. Hamari, J. Do badges increase user activity? A field experiment on the effects of gamification. Comput. Hum. Behav. 2017, 71, 469-478. [CrossRef]

56. Yang, Y.; Asaad, Y.; Dwivedi, Y. Examining the impact of gamification on intention of engagement and brand attitude in the marketing context. Comput. Hum. Behav. 2017, 73, 459-469. [CrossRef]

57. Putz, L.-M.; Hofbauer, F.; Treiblmaier, H. Can gamification help to improve education? Findings from a longitudinal study. Comput. Hum. Behav. 2020, 110, 106392. [CrossRef]

58. Herranz, E.; Guzmán, J.G.; Amescua-Seco, A.; Larrucea, X. Gamification for software process improvement: A practical approach. IET Softw. 2019, 13, 112-121. [CrossRef]

59. Kasurinen, J.; Knutas, A. Publication trends in gamification: A systematic mapping study. Comput. Sci. Rev. 2018, 27, 33-44. [CrossRef]

60. Khandelwal, S.; Sripada, S.K.; Reddy, Y.R. Impact of Gamification on Code review process. In Proceedings of the 10th Innovations in Software Engineering Conference; Association for Computing Machinery (ACM): New York, NY, USA, 2017; pp. $122-126$.

61. Pedreira, O.; García, F.; Brisaboa, N.; Piattini, M. Gamification in software engineering-A systematic mapping. Inf. Softw. Technol. 2015, 57, 157-168. [CrossRef]

62. Porto, D.D.P.; de Jesus, G.M.; Ferrari, F.C.; Fabbri, S.C.P.F. Initiatives and challenges of using gamification in software engineering: A Systematic Mapping. J. Syst. Softw. 2021, 173, 110870. [CrossRef]

63. García, F.; Pedreira, O.; Piattini, M.; Cerdeira-Pena, A.; Penabad, M. A framework for gamification in software engineering. J. Syst. Softw. 2017, 132, 21-40. [CrossRef]

64. Jurado, J.L.; Garces, D.F.; Paredes, L.M.; Segovia, E.R.; Alavarez, F.J. Model for the Improvement of Knowledge Management Processes Based on the Use of Gamification Principles in Companies in the Software Sector. Adv. Hum. Factors Bus. Manag. Train. Educ. 2018, 865, 142-151. [CrossRef]

65. Gasca-Hurtado, G.P.; Gómez-Alvarez, M.C.; Muñoz, M.; Peña, A. A Gamified Proposal for Software Risk Analysis in Agile Methodologies. Adv. Serv. Oriented Cloud Comput. 2019, 1060, 272-285. [CrossRef]

66. Pedreira, O.; Garcia, F.; Piattini, M.; Cortinas, A.; Cerdeira-Pena, A. An architecture for software engineering gamification. Tsinghua Sci. Technol. 2020, 25, 776-797. [CrossRef]

67. Herranz, E.; Colomo-Palacios, R.; de Amescua Seco, A.; Yilmaz, M. Gamification as a disruptive factor in software process improvement initiatives. J. Univers. Comput. Sci. 2014, 20, 885-906. [CrossRef]

68. Herranz, E.; Colomo-Palacios, R.; Seco, A.D.A. Gamiware: A Gamification Platform for Software Process Improvement. Adv. Serv. Oriented Cloud Comput. 2015, 543, 127-139. [CrossRef]

69. Ruiz, M.; Trinidad, M.; Calderón, A. Gamification and Functional Prototyping to Support Motivation Towards Software Process Improvement. In Lecture Notes in Computer Science (Including Subseries Lecture Notes in Artificial Intelligence and Lecture Notes in Bioinformatics); Springer: Cham, Switzerland, 2016; pp. 697-704.

70. Marques, R.; Costa, G.; da Silva, M.M.; Gonçalves, D.; Gonçalves, P. A gamification solution for improving Scrum adoption. Empir. Softw. Eng. 2020, 25, 2583-2629. [CrossRef]

71. Caponetto, I.; Earp, J.; Ott, M. Gamification and Education: A Literature Review. In Proceedings of the 8th European Conference on Games Based Learning; Academic Conferences Ltd.: Berlin, Germany, 2014; p. 50.

72. Borges, S.D.S.; Durelli, V.H.S.; Reis, H.M.; Isotani, S. A systematic mapping on gamification applied to education. In Proceedings of the 29th Annual ACM Symposium on Applied Computing; Association for Computing Machinery (ACM): New York, NY, USA, 2014; pp. 216-222.

73. Dicheva, D.; Dichev, C.; Agre, G.; Angelova, G. Gamification in Education: A Systematic Mapping Study. Educ. Technol. Soc. 2015, $18,75-88$. 
74. Subhash, S.; Cudney, E.A. Gamified learning in higher education: A systematic review of the literature. Comput. Hum. Behav. 2018, 87, 192-206. [CrossRef]

75. Çakıroğlu, Ü.; Başıüyük, B.; Güler, M.; Atabay, M.; Memiş, B.Y. Gamifying an ICT course: Influences on engagement and academic performance. Comput. Hum. Behav. 2017, 69, 98-107. [CrossRef]

76. Chen, S.Y.; Chang, Y.-M. The impacts of real competition and virtual competition in digital game-based learning. Comput. Hum. Behav. 2020, 104, 106171. [CrossRef]

77. Alhammad, M.M.; Moreno, A.M. Gamification in software engineering education: A systematic mapping. J. Syst. Softw. 2018, 141, 131-150. [CrossRef]

78. Souza, M.R.D.A.; Veado, L.F.; Moreira, R.T.; Figueiredo, E.M.L.; Costa, H.A.X. Games for learning: Bridging game-related education methods to software engineering knowledge areas. In Proceedings of the 2017 IEEE/ ACM 39th International Conference on Software Engineering: Software Engineering Education and Training Track (ICSE-SEET), Buenos Aires, Argentina, 20-28 May 2017; pp. 170-179.

79. Petersen, K.; Vakkalanka, S.; Kuzniarz, L. Guidelines for conducting systematic mapping studies in software engineering: An update. Inf. Softw. Technol. 2015, 64, 1-18. [CrossRef]

80. Wieringa, R.J.; Maiden, N.; Mead, N.; Rolland, C. Requirements engineering paper classification and evaluation criteria: A proposal and a discussion. Requir. Eng. 2005, 11, 102-107. [CrossRef]

81. Clarivate. Journal Impact Factor-Journal Citation Reports-Web of Science Group. 2020. Available online: https:/ / clarivate. com/webofsciencegroup/solutions/journal-citation-reports/ (accessed on 5 April 2021).

82. CORE. Computing Research and Education Association of Australasia. 2020. Available online: https://www.core.edu.au/ (accessed on 5 April 2021).

83. Marczewski. Marczewski's Gamification User Types-ELearning Industry. 2020. Available online: https: / / elearningindustry. com/marczewski-gamification-user-types (accessed on 5 April 2021).

84. HP. ABAST»HP Service Manager. 2020. Available online: http://www.abast.es/gestion-ti/soluciones-de-gestion-ti/hp-servicemanager/ (accessed on 5 April 2021).

85. Williams, D.N.; Bell, G.; Cinquini, L.; Fox, P.; Harney, J.; Goldstone, R. Earth System Grid Federation: Federated and Integrated Climate Data from Multiple Sources. In Oil and Gas Exploration in Cuba; Springer Science and Business Media LLC: Berlin, Germany, 2013; pp. 61-77.

86. Csikszentmihalyi, M. Flow: The Psychology of Optimal Experience; Harper \& Row: New York, NY, USA, 1990.

87. ESGF. ESGF-LLNL-Home I ESGF-CoG. 2020. Available online: https:/ / esgf-node.llnl.gov/projects/esgf-1lnl/ (accessed on 5 April 2021).

88. O'Brien, H.L.; Toms, E.G. The development and evaluation of a survey to measure user engagement. J. Am. Soc. Inf. Sci. Technol. 2009, 61, 50-69. [CrossRef] 